Portland State University

PDXScholar

$1-1-2011$

\title{
Motivation in Late Learners of Japanese: Self- Determination Theory, Attitudes and Pronunciation
}

Shannon Guinn-Collins

Portland State University

Follow this and additional works at: https://pdxscholar.library.pdx.edu/open_access_etds Let us know how access to this document benefits you.

\section{Recommended Citation}

Guinn-Collins, Shannon, "Motivation in Late Learners of Japanese: Self-Determination Theory, Attitudes and Pronunciation" (2011). Dissertations and Theses. Paper 191.

https://doi.org/10.15760/etd.191

This Thesis is brought to you for free and open access. It has been accepted for inclusion in Dissertations and Theses by an authorized administrator of PDXScholar. Please contact us if we can make this document more accessible: pdxscholar@pdx.edu. 
Motivation in Late Learners of Japanese: Self-Determination Theory, Attitudes and Pronunciation

\author{
by \\ Shannon Guinn-Collins
}

A thesis submitted in partial fulfillment of the requirements for the degree of

\author{
Master of Arts \\ in \\ Teaching English to Speakers of Other Languages
}

Thesis Committee:

Lynn M. Santelmann, Chair

G. Tucker Childs

Patricia Wetzel

Portland State University

2011 
Abstract

The present study examined a hypothesized relationship between the following variables: intrinsic and extrinsic motivation as described by Self-Determination Theory (Deci \& Ryan, 1985), integrative and instrumental orientation (Gardner \& Lambert, 1972), attitudes toward pronunciation, and accent in English-speaking late learners of Japanese.

Data collection occurred in two steps: First, English-speaking participants completed three questionnaires designed to measure their motivation and attitudes toward pronunciation; they then provided speech samples in Japanese. Native speakers of Japanese then rated these speech samples holistically on a scale of 1 to 5 , with 1 indicating a strong foreign accent, and 5 indicating a native accent. Scores on the questionnaires were then correlated with the accent ratings.

None of the English-speaking participants were judged as native or near-native speakers of Japanese. However, results demonstrated a significant positive correlation between ratings of accent and two variables: Intrinsic Motivation Toward Accomplishment and attitudes toward pronunciation. The statistical analysis also revealed a positive correlation between integrative and instrumental orientation and extrinsic motivation, suggesting a relationship between measures of orientation and extrinsic motivation as well.

These results highlight the importance of including Self-Determination Theory in the area of second/foreign language acquisition research, as well as clarifying the role of motivation and attitudes toward pronunciation in the present context of late learners of Japanese. 


\section{Dedication}

To my husband, Matt, for his enduring patience and support throughout research and revisions. 


\section{Acknowledgements}

There are so many people to thank that I can't possibly fit them all in a page, but I will attempt to. First and foremost, thank you to my participants and judges, for your generosity with your time and your thoughts. This quite literally could not have be done without you.

To my advisor, Lynn Santelmann, I cannot possibly thank you enough for your many hours talking with me and reading my drafts. You have made me a stronger writer and a better scholar, and I am so glad that I had the opportunity to work with you.

To the many other professors in my department and others, thank you for your support and the impromptu hallway meetings. Thank you to Kathy Harris for allowing me to be a slightly distracted TA, to Susan Conrad for your encouragement when I embarked on this thesis writing process, and to Keith Walters for the discussions of SelfDetermination Theory and the pep talks. Thank you to the members of my committee, Tucker Childs and Pat Wetzel for invaluable comments and ideas.

To my peers and friends, thank you for reading pages and giving me comments, thank you for asking about my research and then letting me ramble for far too long.

Finally, thank you to my parents for their tireless enthusiasm for my work and for their life-long support, and to Matt for always reminding me when to take a break. 
Table of Contents

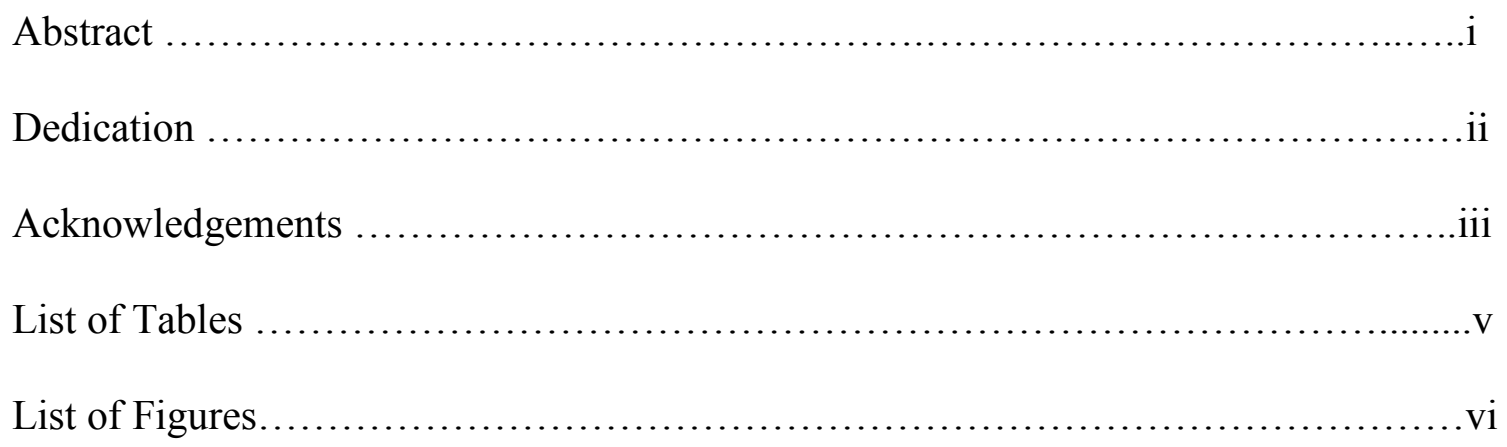

Chapter 1

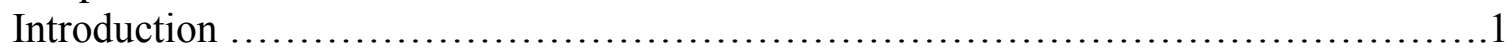

Chapter 2

Review of Literature ....................................................4

Chapter 3

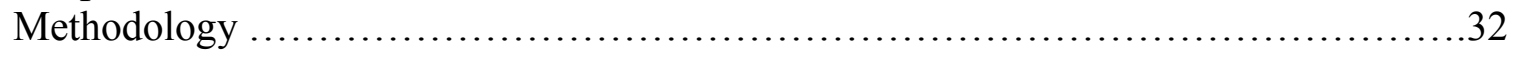

Chapter 4

Results ................................................................. 39

Chapter 5

Discussion ...........................................................49

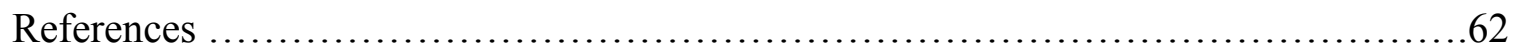

Appendices

A. Interest Form..................................................68

B. Participant Informed Consent..........................................69

C. Judge Informed Consent............................................... 71

D. Participant Language Background..................................... 73

E. Academic Motivation Scale.......................................... 74

F. Mini Academic Motivation Test Battery..................................76

G. Pronunciation Attitude Inventory................................... 78 
List of Tables

Table 1: Seven subtypes of motivation according to Self-Determination Theory........8

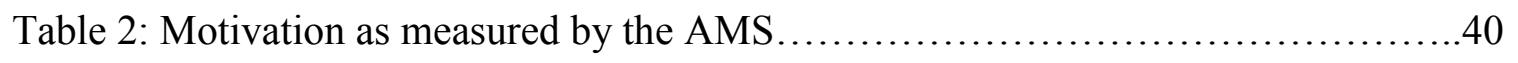

Table 3: Integrative and instrumental orientation as measured by the AMTB ..........40

Table 4: Pronunciation Attitude Inventory results...............................41

Table 5: Accent ratings per participant and sentence, averaged over judges............42

Table 6: Summary of correlations.........................................44

Table 7: Three subtypes of intrinsic motivation as measured by the AMS...............46

Table 8: Summary of intrinsic motivation subtype correlations.......................46

Table 9: Summary of extrinsic motivation and orientations correlations...............48 
List of Figures

Figure 1: Trend line of accent rating and Pronunciation Attitude Inventory results.......45

Figure 2: Trend line of accent rating and intrinsic motivation toward accomplishment...47 


\section{Chapter 1}

\section{Introduction}

\section{Background}

The role of age in second language acquisition has long been established: children are often able to acquire second languages to native-like fluency, whereas adults are likely to get stuck somewhere in a transitional zone, having acquired enough language to function easily enough in their L2, but remaining unable to pass as a native speaker due to issues of syntax or accent. A rare few, however, may be able to surpass those expected boundaries, and pass as native speakers of a second language (e.g., Bongaerts, Planken, \& Schils, 1995; Ioup, Boustagui, El Tigi \& Moselle, 1994). The variability in ultimate attainment for adult learners of a second language is particularly important to those of us who teach this population: we must have some reason to account for this variation.

As an adult language learner of Japanese, I found myself fascinated by the variability I saw in my fellow learners: some seemed to progress easily and rapidly with grammar, achieving pronunciation that was excellent, if not entirely native-like; others seemed to stall and struggle, fighting with every construction and every syllable. I also began to notice that many students had vastly different reasons for coming to class everyday: some planned to live and work in Japan, others simply needed to fulfill a language credit. I found it difficult to explain why I was driven to learn Japanese, able to say at that point only that I was fascinated by how the language fit together, by the sound of it in my ears and the way it felt to speak it - the sheer wonder of communicating with someone else's words. 
Later, as a student of linguistics, I realized that these reasons were different forms of motivation, and what I experienced was called intrinsic motivation. I was motivated to learn not because I had the opportunity to use the language regularly, or because it was somehow necessary for me to know it, but simply because the act of studying it and acquiring new knowledge of a foreign language brought me such joy. I began to wonder what, if any connection there might be between motivation and the varying success I saw in adult L2 learners, particularly in terms of their pronunciation.

Purpose

These experiences as a language student and linguist gradually led me to the topic of my thesis: motivation and pronunciation. More specifically, in this study I explored the relationship between motivation and pronunciation in proficient late learners of Japanese as a foreign language, and investigated the relationship between these two factors. During my initial research into constructs of motivation and pronunciation, I also discovered that a learner's attitude toward pronunciation played a role distinct from motivation, and decided to incorporate it as well.

My goal in this study was to discover what role motivation or attitude toward pronunciation play in the accent of late learners of Japanese. In order to best characterize the motivation of my participants, I chose to use two major models of motivation: SelfDetermination Theory (Deci \& Ryan, 1985) and integrative and instrumental orientation (Gardner \& Lambert, 1972). I worked with students in the Japanese department at a university in the Pacific Northwest to gather data, including recorded speech samples. My hope in doing all of this was to find some speakers who betrayed the expectations set by 
so many when dealing with adult or late learners of a second language: that the pronunciation of late learners would never match that of a native speaker. I also hypothesized that I might find a connection between intrinsic motivation as described by Deci and Ryan (1985) and accent, and between a positive attitude toward pronunciation and accent. While I did not find any learners who were able to pass as native speakers during this study, I did find strong and significant correlations between intrinsic motivation and accent, and between a positive attitude toward pronunciation and accent.

Overview of the Thesis

In the following chapters, I explore the role of motivation and attitude toward pronunciation in the accents of English L1 late learners of Japanese. In Chapter 2, I review the pertinent literature and provide detailed descriptions of Self-Determination Theory (Deci \& Ryan, 1985) and integrative and instrumental orientation (Gardner \& Lambert, 1972), an overview of the accentual challenges facing English-speaking learners of Japanese, and a discussion of the Critical Period Hypothesis. In Chapter 3, I provide a description of the methodology employed in this study. Chapter 4 contains the results, and the concluding Chapter 5 provides the answers to my research questions, a discussion of their theoretical and pedagogical implications, an explanation of the limitations of my study, and suggestions for future research. 


\section{Chapter 2}

\section{Review of the Literature}

The purpose of this study was to examine English-speaking learners of Japanese who were not exposed to their second language until after the onset of puberty, and explore the role that motivation and attitudes toward pronunciation may have played in their success or lack thereof of achieving excellent pronunciation.

The research regarding motivation in language learning is truly vast, spanning decades of study and involving dozens of researchers (Deci \& Ryan, 1985; Deci, Vallerand, Pelletier, \& Ryan, 1991; Dörnyei, 1994, 2001; Gardner \& Lambert, 1972; Gardner, 1985; Gardner \& Tremblay, 1994; Noels, 2001; Noels, Pelletier, Clément, \& Vallerand, 2000; Pae, 2008; Smit, 2002; Smit \& Dalton, 2000). The research regarding successful late learners of a second language is also extensive, though markedly less so (Bongaerts et al., 1995; Bongaerts, van Summeren, Planken, \& Schils, 1997; Ioup et al., 1994; Marinova-Todd, Marshall, \& Snow, 2000; Moyer, 1999). These two phenomena are not unrelated, as has been remarked upon by a number of those researchers involved. Motivation in many forms has been amply demonstrated to lead to success in second language acquisition, though its connection to the success of late learners of a second language has yet to be deeply explored or very well understood.

The role that motivation plays in the acquisition of L2 phonology among late learners is an area that has not yet been thoroughly researched, and is therefore in need of further study. Some late learners are more able than others to achieve excellent, or more native-like pronunciation, despite their age of acquiring it, but why this is the case 
remains a mystery. It is this mystery that I explored in this study, to reach a greater understanding of the relationship between motivation and accent in the speech of late learners of a second language.

In the following sections, I describe in detail the two theories of motivation that provide the framework for my study and the pertinent prior research in which they have been applied. I also discuss attitudes toward pronunciation and the findings that are most germane to my own research. I include a brief outline of the accentual difficulties for English-speaking learners of Japanese, and comment in closing on a number of studies that have explored pronunciation in exceptional learners.

\section{Motivation and Language Learning}

Motivation has long been "established...as a principal determinant of second language acquisition, comparable in its impact to another well-researched learner variable, language aptitude" (Dörnyei, 2001, p. 43). Since its introduction to the field of second language acquisition research, motivation has been discussed and researched within a variety of contexts, leading to the construction of a number of frameworks and theories. Two of the most prominent theories are Gardner and Lambert's (1972) integrative and instrumental orientation, and Deci and Ryan's (1985) Self-Determination Theory. I employed both in my study. In these first four sections of my literature review, I describe integrative and instrumental orientation and Self-Determination Theory in detail, discuss the relationship between them, and their prior application to research regarding achievement in language learning and pronunciation. 
Integrative and Instrumental Orientation

Gardner and Lambert's (1972) conceptualization of integrative and instrumental orientation is one of the most widely-respected and researched theories of motivation in the field of second language acquisition. In their model, orientation and motivation are two distinct concepts: orientation is "a class of reasons" (Gardner \& Tremblay, 1994, p.361) for why an individual may choose to study a language, whereas motivation is defined as a combination of motivational intensity, attitudes toward learning the L2, and the desire to learn the L2 (Pae, 2008). Gardner and Lambert's (1972) theory allows for two types of orientation governing the learner's behavior: integrative and instrumental. Integrative orientation denotes a desire on the part of the learner to be like members of the target language community, and to enter that community to the fullest extent possible (Gardner \& Lambert, 1972). Instrumental orientation, on the other hand, is the desire to learn a language to achieve a practical goal (such as using the target language for professional purposes) rather than the interpersonal benefits that might come from integration (Garner \& Lambert, 1972).

The concepts of integrative and instrumental orientation have been highly influential in the field of L2 motivation research. However, as thorough and wellresearched as the construct of integrative and instrumental orientation is, it has been noted that "the main emphasis... is on general motivation components grounded in the social milieu rather than in the foreign language classroom" (Dörnyei, 1994, p.273). In other words, integrative and instrumental orientation may be more suited to environments in which learners have more opportunity to communicate with members of the target community or use the target language in their daily lives, as opposed to the foreign 
language classroom, where such opportunities may or may not be available. It is for this limitation, as well as the sophistication and applicability of Self-Determination Theory (SDT), that my own study was not solely confined to the framework of integrative and instrumental orientation, but also used the motivational types as set forth by SDT.

\section{Self-Determination Theory}

Self-Determination Theory (Deci \& Ryan, 1985) was developed in the field of educational psychology and has only recently been applied to language learning. SDT identifies three main categories of motivation: intrinsic motivation, extrinsic motivation, and amotivation. Intrinsic motivation is inward motivation, that is, when a learner undertakes learning for its own sake, and not for any external reward. Extrinsic motivation is outward motivation, in which a learner undertakes learning to pursue some outward achievement (e.g., grades or employment) or to avoid punishment. Amotivation is a lack of motivation, which occurs when a learner perceives no relationship between their actions and the results of those actions. These three types of motivation are placed on a continuum demonstrating how self-determined each type is. Behavior may be described as more self-determined if it is decided upon and regulated by an individual's own desires or needs, e.g., a student who chooses to learn a language simply for the enjoyment and interest of learning that language is exhibiting highly self-determined behavior and therefore high intrinsic motivation. Behavior is considered less selfdetermined if it is regulated by an outside force, such as a student who studies to maintain a grade in a class, demonstrating extrinsic motivation. Thus, intrinsic motivation is the most self-determined and amotivation is the least. 
There are three subtypes of both intrinsic and extrinsic motivation, described by Vallerand et al. (1992) as follows: intrinsic motivation to know, which is engaging in an activity for the enjoyment experienced while learning something new; intrinsic motivation toward accomplishments, which is engaging in an activity for the enjoyment gained from attempting to accomplish something; and intrinsic motivation to experience stimulation, which is engaging in an activity to experience stimulation of some variety, for example sensory or aesthetic. Vallerand et al. (1992) describe the three subtypes of extrinsic motivation as follows: identified regulation, in which an individual believes that the activity they are engaged is valuable and important; introjected regulation, in which an individual has somewhat internalized the reasons for engaging in an activity; and finally external regulation, in which an individual engages in a behavior due to some external reasons, such as rewards, or the threat of punishment. These subtypes (in this case specific to language learning) are summarized in Table 1.

Table 1 Seven subtypes of motivation according to Self-Determination Theory

\begin{tabular}{|l|l|l|}
\hline Motivation Type & \multicolumn{1}{|c|}{ Subtype } & \multicolumn{1}{c|}{ Behavior } \\
\hline intrinsic & to know & $\begin{array}{l}\text { learning a language for the sake of learning it, } \\
\text { because of the enjoyment that is derived from } \\
\text { learning it }\end{array}$ \\
\hline intrinsic & $\begin{array}{l}\text { toward } \\
\text { accomplishments } \\
\text { comes in mastering or acquiring that language }\end{array}$ \\
\hline intrinsic & $\begin{array}{l}\text { to experience } \\
\text { stimulation }\end{array}$ & $\begin{array}{l}\text { learning a language for the fun and excitement } \\
\text { of gaining new ability in that language }\end{array}$ \\
\hline identified regulation & $\begin{array}{l}\text { learning a language because the individual } \\
\text { believes it is important for them, personally, to } \\
\text { learn }\end{array}$ \\
\hline
\end{tabular}




\begin{tabular}{|l|l|l|}
\hline Motivation Type & \multicolumn{1}{|c|}{ Subtype } & \multicolumn{1}{c|}{ Behavior } \\
\hline extrinsic & introjected regulation & $\begin{array}{l}\text { learning a language because some formerly } \\
\text { external reasons have been internalized }\end{array}$ \\
\hline extrinsic & external regulation & $\begin{array}{l}\text { learning a language to accomplish a specific } \\
\text { goal, such as doing well on a test, or fulfilling } \\
\text { the requirements of a degree }\end{array}$ \\
\hline none & amotivation & $\begin{array}{l}\text { motivation to learn the language has been lost - } \\
\text { individual perceives no relation between their } \\
\text { actions and the outcomes }\end{array}$ \\
\hline
\end{tabular}

A fourth subtype of extrinsic motivation, integrated regulation, is included on the original scale of self-determination, but it has not been explored in the L2 context given that it has been found too difficult to distinguish from identified regulation (Noels et al., 2003; Pae, 2008). Contrary to both extrinsic and intrinsic motivation, and representing behavior that is not self-determined, is amotivation. As described previously, in amotivation, individuals perceive no relationship between their behavior and the outcomes of a given situation (Vallerand et al., 1992).

Various relationships between Deci and Ryan's (1985) SDT and Gardner and Lambert's (1972) integrative and instrumental orientation have been suggested, but the relatedness of the theories remains inconclusive. For this reason, I included both in my own study. 
The Relatedness of Integrative and Instrumental Orientation and Self-Determination Theory

Comparisons of SDT with the more traditional theory of integrative and instrumental orientation have been recently undertaken by a handful of researchers (e.g., Noels, 2001; Noels et al., 2003; Pae, 2008). Noels' (2001) study of English-speaking learners of Spanish addressed the relationship between integrative orientation and intrinsic and extrinsic motivation, but did not focus at all on instrumental orientation. She also investigated the role of the teacher in motivation, finding that the more controlling the teacher was perceived to be, the less intrinsically motivated the students were likely to be (Noels, 2001). Noels further found that integrative orientation was more strongly associated with intrinsic motivation and identified regulation than were either external regulation or introjected regulation. In other words, according to Noels' results, integrative orientation could be considered self-determined behavior. She maintained, however, that integrative orientation and intrinsic motivation were two distinct constructs and that "enjoying the challenge of language learning and desiring interaction with the L2 community [were] orientations that speak to relatively separate issues" (Noels, 2001, pp.137-138). She suggested that this distinction supports the concept that there may be two areas of motivation, one for the immediate setting in which an individual is learning the language, and the other pertaining to broader societal and group issues. This individual learning is more in line with the types of motivation as described by SDT, in which an individual studies a language for their own reasons. The societal and group issues, however, fit the mold of integrative and instrumental orientation, as in integrative 
orientation the individual studies a language to become part of a group or society, rather than for their own individual enjoyment or sense of accomplishment.

Pae (2008), in a study of Korean EFL learners, compared intrinsic and extrinsic motivation to integrative and instrumental orientation. He found that instrumental orientation was not significantly different from external regulation, the least selfdetermined behavior aside from amotivation. He did find, however, that instrumental orientation was significantly different from identified and introjected regulation, as well as all three subtypes of intrinsic motivation. Integrative orientation was statistically different than all six subtypes of intrinsic and extrinsic motivation. Pae's results differed from those of Noels (2001) in the apparent lack of connection between integrative orientation and intrinsic motivation. While Noels maintained that integrative orientation and intrinsic motivation were distinct constructs, according to her results integrative orientation could be considered a self-determined behavior, and was somewhat related to intrinsic motivation. Pae did not find any relationship between integrative orientation and intrinsic motivation.

In a later study, Noels et al. (2003) also found a correlation between instrumental orientation and external regulation. Their study was based in French-English bilingual classes at the University of Ottawa, and was designed not only to compare the various subtypes of motivation to instrumental orientation (though not integrative orientation), but also to test the general applicability of the SDT framework to the L2 learning context. In a mindset at odds with the results of Noels et al. (2003), Noels (2001) and Pae (2008), which all place integrative orientation firmly outside the realm of extrinsic motivation, Gardner (1985) himself stated that both integrative and instrumental 
orientation should be considered forms of extrinsic motivation, as they "indicate that the language is being learned in order to satisfy some goals not simply because of an intrinsic interest in the language itself" (p. 12). In other words, when a student undertakes the learning of a language in order to communicate with members of the target language community, they are pursuing an external goal. Likewise, when a student undertakes the learning of a language in order to complete the requirements for their bachelor's degree, that is also an external reason. Gardner's own views seem to conflict with those of other researchers (e.g., Noels, 2001; Pae, 2008), a difference he noted himself, commenting in particular on a statement made by Jakobovits (1970), who referred to "intrinsicintegrative orientation" and "extrinsic-instrumental orientation" (p. 256), apparently conflating the constructs. Note here that Gardner and Jakobovits' conceptualizations of intrinsic and extrinsic motivation predate SDT by fifteen years, and the terms intrinsic and extrinsic were not used within the framework established by Deci and Ryan (1985). As is evident in these disparate viewpoints, despite many years of research and multiple studies, the relatedness of SDT and integrative and instrumental orientation is not yet clear. We may draw some general conclusions that the theories are perhaps overlapping, in that integrative and instrumental orientation may fall within the extrinsic motivation category, but the extent to which they overlap is yet unknown. Due to the lack of clarity about whether the two theories measure the same constructs or entirely distinct ones, the necessity of including both theories becomes ever more obvious: with so many varying viewpoints, how else are we to gain a clear picture of a student's motivation?

One of the great differences between integrative and instrumental orientation and SDT lies in their origins: Gardner and Lambert (1972) conceptualized integrative and 
instrumental orientation specifically to account for aspects of motivation in language learning. SDT, on the other hand, began not as a theory of motivation in L2 learning, but rather as a more general theory of motivation in learning as a whole.

Another great difference, one that is frequently neglected in discussions regarding motivation, is that orientation and motivation are two different constructs. Integrative and instrumental describe types of orientation, in other words, a student's reasons for learning a language. Intrinsic and extrinsic describe types of motivation, or the complex combination of a student's desire to learn an L2, attitudes toward that L2 and motivational intensity directed toward that learning. I mentioned this difference at the beginning of my review of the literature, but the distinction bears repeating and clarifying, since the terms orientation and motivation are so frequently conflated and confused.

\section{Variability in Motivation}

One final important fact about motivation and orientations is that they are variable. In other words, a learner's motivation or orientation may shift and change over time; it is not static or necessarily stable. In a study of students of French, Gardner, Masgoret, Tennant and Mihic (2004) found that high-achieving students maintained higher levels of motivation and integrative orientation over the course of the term, while lower-achieving students had notably lower levels of motivation and lessened integrative orientation by the end of the term. Other researchers (e.g., Noels, 2001; Dörnyei, 1994) have suggested that certain orientations or motivations might also be more likely to be exhibited by learners depending on the social context in which their language learning 
takes place. Clearly, there are a number of factors that may affect a language learner's motivation and achievement, and while they are not dealt with in this study, it is necessary to be aware of them.

\section{Motivation and Academic Achievement}

As a theory of motivation, SDT has been applied in many educational settings and found to be a very useful indicator of achievement in an academic context. Deci and Ryan (1985) reviewed a number of experimental studies demonstrating the importance of intrinsic motivation in general academic learning, leading them to state that "one can reasonably conclude that intrinsic motivation is associated with improved learning" (p. 257). This learning was measured by grades and classroom performance.

In more recent years, SDT has begun to be applied more specifically to achievement in language learning. The results of some of these studies, discussed in some detail below, were more germane to my own study. SDT has not been commonly applied to second language acquisition research, but it is particularly applicable in that it affords levels of distinction in the subtypes of motivation that are not available in other models. Due to this, research in language learning should more often employ SDT. This was one of my own goals for this study: to add to the body of literature regarding SDT and second language acquisition.

\section{Motivation and Language Learning}

Despite the fact that motivation has a long history as an important variable in language learning, researchers are not always in agreement as to which aspects of 
motivation are most important (Gardner \& Lambert, 1972; Moyer, 1999; Noels, 2001; Pae, 2008; Tachibana, Matsukawa, \& Zhong, 1996). Gardner and Lambert (1972) have suggested that the desire for integration encourages the long-term motivation that is necessary to successfully learn a second language. In a series of studies of Englishspeaking students of French in three high schools located across the United States, Gardner and Lambert (1972) discovered that in one of the schools, integrative orientation, as well as interaction with members of the target culture, led to higher achievement in French as measured by a battery of tests, including a number of measures from the Cooperative French Listening Comprehension Test, the students' grades in their French course, a self-evaluation of the students' abilities, and tests of accent and complexity of speech (pp. 24-26). The students' orientation was measured with the Academic Motivation Test Battery (Gardner \& Lambert, 1972)

Research into the effects of instrumental orientation is more mixed. Moyer (1999) found instrumental orientation to be associated with lower achievement in learning a language than an integrative orientation. On the other hand, Gardner and Lambert (1972), in one of the schools included in the study described above, found that both instrumental and integrative orientation appeared to be correlated with achievement as measured by grades and various tests (pp. 24-26).

Other studies have examined intrinsic and extrinsic motivation and their effect on language learning. In a comparative study of Japanese and Chinese students learning English, Tachibana et al. (1996) found that intrinsic motivation, as measured by a questionnaire, was more strongly correlated with success in the English classroom in terms of grades than was extrinsic motivation or instrumental orientation. While 
employing the terms intrinsic and extrinsic, however, they did not frame their study within SDT and so the precise relationship of the motivation they found is cast into some doubt.

Pae (2008), in the study of Korean EFL learners discussed previously, not only compared the two models of motivation to one another, but also investigated how they correlated with achievement in the EFL classroom. He found that "intrinsic motivation is the most powerful orientation variable that is related to L2 achievement in the Korean EFL context” (p. 20).

Given the studies described above, the applicability of the multiple subtypes of motivation as set forth by SDT becomes clear: intrinsic motivation appears to be directly related to L2 achievement. My own study was within a foreign language classroom context, incorporating elements of the studies conducted by both Noels (2001) and Pae (2008). It seemed possible that intrinsic motivation might have the same effect in other contexts as it has in these studies; for example, the context of English-speaking learners of Japanese. My study, however, in contrast to those described above, did not address general academic or classroom achievement, but rather achievement in the area of pronunciation.

\section{Motivation and Pronunciation}

Unlike the relationship between motivation and academic achievement or more general language learning, the relationship between motivation and achievement specifically in pronunciation has not been thoroughly explored. In two studies examining the pronunciation of EFL learners in Vienna, Smit (2002) and Smit and Dalton (2000) 
suggested a three-part model of motivation in pronunciation. This model incorporated the following: learner-related factors, such as language use anxiety and self-perception of L2 accent; classroom-related factors, such as teaching styles and learning strategies; and subject-related factors, such as integrativeness and intrinsic and extrinsic motives (p. 232). Although intrinsic and extrinsic motivation were mentioned, the concepts were not clearly situated within the framework of SDT, nor were the various subtypes addressed. Furthermore, integrative orientation was placed in the same branch of this tripartite model as intrinsic and extrinsic motivation, and so the relationship between these various types of motivation and orientation was not clear. Neither of these studies employed the measures used in my study to investigate motivation or orientation. These measures are the Academic Motivation Scale (Vallerand, Blaise, Brière \& Pelletier, 1989) for motivation as described by SDT, and the mini Academic Motivation Test Battery (Gardner \& Lambert, 1972; Gardner \& MacIntyre, 1993) for integrative and instrumental orientation their measurement of motivation and orientation.

Perhaps even more problematically, the language background of their sample was not described, so factors that might play into achievement in pronunciation, such as age of acquisition, were not addressed. In terms of results, Smit and Dalton (2000) found that extrinsic motivation appeared to be slightly stronger among the majority of the participants, but the relationship this motivation had with achievement was not made clear. Nor did Smit (2002) appear to find any strong link between motivation and achievement, finding instead that the perceived relevance of the course in which the participants were enrolled seemed to be the most important factor. 
A recent study by Polat (2010) did examine participants' motivation and relate it to their pronunciation, though he employed a self-regulation questionnaire rather than the Academic Motivation Scale and only examined extrinsic motivation, rather than both intrinsic and extrinsic motivation. In this study, Polat looked specifically at gender differences in motivation and accent in a population of Kurdish middle and high school learners of Turkish. He found that female students had a higher average accent rating than male students, and that there was a significant correlation between integrated orientation (a subtype of extrinsic motivation) and accent among both male and female students. There are a few crucial differences between my study and Polat's, namely his focus on extrinsic motivation, and the age of his participants at the beginning of acquisition. His participants had begun their study of Turkish at the age of six or seven, and so his study did not have the particular focus on late learners and the limitations posed by the critical period.

A number of researchers examining pronunciation specifically in late learners have touched upon the likely importance of motivation (Bongaerts et al., 1995, 1997; Moyer, 1999), though again none of them have employed the Academic Motivation Scale (Vallerand et al., 1989) or the mini Academic Motivation Test Battery (Gardner \& Lambert, 1972; Gardner \& MacIntyre, 1993). There is a general agreement that motivation must be important, but no one has probed further into what types of motivation might be at work, or precisely how important they might be. More specifically, the relationship between the subtypes of motivation as described by SDT and achievement in pronunciation has yet to be investigated. This, as well as the potential 
importance of integrative and instrumental orientation, is precisely what I investigated in this study.

There are many other potential variables affecting pronunciation in late L2 learners, not least of which is attitude toward pronunciation. This is an area that has not received much attention in research thus far, but there has been some indication of its importance (Elliot, 1995a, 1995b).

\section{Attitudes Toward Pronunciation}

Unlike the models of motivation, research regarding attitudes has been developed specifically to relate to achievement in pronunciation. In a study of adult leaners of Spanish, Elliott (1995a) developed and administered a questionnaire called the Pronunciation Attitude Inventory (PAI), designed to measure students' attitudes toward the importance of pronunciation teaching in the classroom, and their own assessment of their abilities to achieve native-like pronunciation. The participants' responses to this questionnaire were then correlated with their abilities as measured by a test of their

pronunciation. The pronunciation test included mimicking pronunciation at the word and sentence level, pronunciation of written words, and pronunciation in spontaneous conversation (Elliott, 1995a). Attitude, as measured by the PAI, was found to be the most accurate predictor of pronunciation accuracy (Elliott, 1995a, 1995b). However, none of the participants fell within the native speaker range, which indicated that, at least at the point of testing, all participants spoke with some degree of a non-native accent. In the spontaneous speech section, participants were graded on a scale of 1 to 5 , with 1 indicating very poor pronunciation and 5 indicating native pronunciation. The highest 
score obtained was a 4, though it was never made clear what this score indicated in terms of pronunciation ability. The judges, however, were all aware of the fact that the participants were non-native speakers of Spanish and this knowledge may have influenced their judgments. Judges were instructed to ignore grammatical errors, but these may have also contributed to the assessment of none of the participants being rated as native speakers. In addition, Elliot made no mention of a native-speaker control being included in the participants to ensure intra-rater reliability of the judges' ratings, though inter-rater reliability was found to be very high.

Because attitude toward pronunciation was found to be an accurate predictor of pronunciation accuracy, I decided to explore it within the context of my own study, along with the measures of motivation. Furthermore, Elliot's (1995a, 1995b) studies were conducted in university foreign-language classrooms, so the context in which I undertook my study - upper-level Japanese as a foreign language classrooms - was parallel and directly comparable. The relationship between attitudes toward pronunciation and accent in a foreign language is surely an area deserving of more study if we intend to draw any lasting conclusions.

In contrast to Elliot's (1995a, 1995b) results, a number of researchers (e.g., Bongaerts et al., 1995; Ioup et al., 1995) have found that some late learners appear to achieve native-like or near native-like pronunciation in a second language, even if it is acquired in adulthood. Elliot (1995) was looking only for correlations between pronunciation ability and certain variables, including attitudes toward pronunciation, rather than deliberately seeking out those students who might have had native-like abilities, so it is possible that this study with a more specific group of participants might 
have yielded very different results. Before addressing the research involving highly successful late learners, however, I will briefly discuss some of the difficulties that English L1 learners may face in pronouncing Japanese, and the features that might contribute to accented speech.

\section{Japanese and English Accents}

To understand the difficulty that language learners face in acquiring the pronunciation of a new language, it is necessary to have some understanding of the primary differences between the learner's L1 and L2. In this section, I will give a brief outline of the major differences between English and Japanese, and comment on the potential challenges an American English L1 learner of Japanese might face in acquiring a native-like Japanese accent.

There are multiple dialects of Japanese, primarily regional. For the purposes of my study, I used Tokyo Japanese as the standard form, given that it was most common among my native speaker participants and is "virtually equivalent to so-called Standard Japanese" (Haraguchi, 1999, p. 6).

\section{Pitch Accent}

Many scholars argue that pitch accent appears to be particularly difficult for American English L1 of Japanese (e.g., Shport, 2008; Vance, 1987). There are at least two pitch levels in Japanese (high and low), and there are minimal or near-minimal pairs of pitch. A common example to illustrate the importance of pitch accent and the potential difficulty that learners face are the words hási, 'chopsticks', hasí, 'bridge' and hasi, 
'end'. The last two, hasi and hasi both follow a low-high accent pattern when spoken in isolation, and are only distinguishable when another word or phrase follows (Okada, 1999). Despite the fact that English and Japanese share no common ancestry and are typologically quite different, Haraguchi (1999) states that pitch accent in Tokyo Japanese and the stress accent system of English are not entirely dissimilar. However, 'not entirely dissimilar' and 'easy to learn' are not necessarily synonymous, and many teachers of Japanese and researchers report pitch accent to be a problematic area (e.g., Shport, 2008). American English L1 learners are subject to two potential errors with pitch accent: they are likely to either impose the English stress accent system onto Japanese, or they are unable to perceive pitch accent, and therefore unable to mimic it ( $\mathrm{P}$. Wetzel, personal communication, May 16, 2011). A recent study by Shport (2008) found that American English L1 learners of Japanese were unable to either perceive or produce accented words in Japanese at a greater than chance level. P. Wetzel has also stated that pitch accent is the most difficult aspect of Japanese pronunciation for many learners, particularly the fact that loudness is not as salient in Japanese as it is in English (personal communication, April 6, 2011). For example, when one speaker corrects another, English speakers are likely to have an exchange such as this (capital letters indicate stressed words):

A: It IS there.

B: No, it's NOT there.

In Japanese, however, the equivalent exchange would not have this change in loudness, but Speaker B would instead use the particle wa to indicate the focus:

\section{A: Soko ni arimasu yo.}


B: Iie, soko ni wa arimasen.

\section{Morae and Syllables}

A second major difference between Japanese and English is the fact that Japanese is considered a mora-timed language, whereas English is considered a stress-timed language (Kubozono, 1999). A mora is essentially a unit of timing, in that each mora takes approximately the same amount of time to say. Morae may be formed in the following ways: $\mathrm{V}, \mathrm{CV}, \mathrm{CyV}$, and $\mathrm{C}$ (which is constrained to geminates, such as ki-t-te, 'stamp' and a syllabic nasal as in h-on, 'book').

Syllables may be defined phonetically as units containing peaks of prominence or sonority in a one-to-one relationship (Ladefoged, 1982), and while they are used in Japanese, they are not the primary method of dividing words, as they are in English. Furthermore, syllables and morae do not operate in a one-to-one relationship. For example, hon, 'book', is two morae but one syllable. Kekkon, 'marriage,' is four morae (ke-k-ko-n) but two syllables (kek-kon). Syllables are important in Japanese, however, as they are the bearers of accent (Kubozono, 1999; McCawley, 1978; Vance, 1987).

\section{Vowel Devoicing}

A third major difference between English and Japanese is the treatment of vowels. In Japanese, the high vowels [i] and [u] are devoiced when they occur between voiceless consonants, or word-finally and preceded by a voiceless consonant (Hibiya, 1999). For example, the $[\mathrm{u}]$ is devoiced in desu, 'to be', which results in the pronunciation [des]. 
Age of Acquisition

Finally, perhaps the greatest challenge of all facing the learners of Japanese who participated in this study is the fact that they all began their study of Japanese after the onset of puberty, and thus may face acquisition hurdles that might not pertain to those who began their study at a younger age. I should note here that the accentedness ratings used in my study were holistic, and due to this, it is not possible to define precisely how much contribution each of the above elements makes in the accent in a non-native speaker of Japanese.

\section{Accent, the Critical Period Hypothesis and Exceptional Learners}

\section{The Critical Period Hypothesis}

It is widely accepted among linguists and laypeople alike that learners who begin their study of a second language after puberty are rarely able to achieve the near-native or native-like fluency that is commonly found in younger learners (Abrahamsson \& Hyltenstam, 2008). This Critical Period Hypothesis was introduced by Lenneberg (1967), who proposed that after the onset of puberty it is no longer possible to achieve native-like ability in a second language, referring to this time before puberty as the critical period. Since its original conceptualization, however, the Critical Period Hypothesis has undergone a number of shifts, and linguists and developmental psychologists have come to the conclusion that there is no single cut off point for the acquisition of a second language, but rather a general decline in abilities as an individual ages. Furthermore, it has been hypothesized that different aspects of a language may be subject to different constraints, or the ability to attain those aspects may be lost at different ages. In a review 
of a great quantity of studies regarding the existence of a critical period in second language acquisition, Long (1990) stated that

the [second language]... results all suggest that SL phonological attainment is strongly conditioned by learner age. Specifically, a native-like accent is impossible unless first exposure is quiet early, probably before 6 in many individuals and by about age 12 in the remainder. Very high standards can be attained starting later of course, but not, it seems, native-like standards (p. 266).

A number of researchers in more recent years, however, have found results to the contrary, and have posited that some individuals may not be subject to the constraints of the critical period. These individuals are sometimes known as exceptional learners (Birdsong, 1992; Bongaerts et al., 1995, 1997; Ioup et al., 1994; Moyer, 1999), talented learners (Schneiderman \& Desmarais, 1988a, 1988b) or exceptionally talented learners (Abrahamsson \& Hyltenstam, 2008).

\section{Ultimate Attainment in Phonology and the Potential Importance of Motivation}

A number of studies regarding successful late learners have touched upon the issue of motivation, with differing levels of detail. One of the most comprehensive studies of exceptional learners was by Ioup et al. (1994), in which the researchers thoroughly examined the speech of two exceptional learners of Arabic. Both had been exposed to the language for the first time well after the close of the critical period, one in a naturalistic manner, without formal instruction (Julie), and the other through universitylevel instruction, as well as immersion (Laura). In terms of accent, both Julie and Laura were rated as native speakers by 8 out of 13 native speaker judges. The judges who rated them as non-native speakers were described as "particularly sensitive to phonemic distinction" (Ioup et al., 1994, p. 80), and it was made clear that Julie and Laura could 
pass for native speakers on a regular basis. Ioup et al. also mentioned the importance of motivation in their participants' high achievement in second language acquisition, but did not take any steps to discover what types of motivation might relate to this achievement.

In two studies on the attainment of native-like phonology in late learners of English, Bongaerts et al. (1995, 1997) specifically mentioned that their subjects were all highly motivated to be able to speak English without a Dutch accent, due to their professional ambitions. The authors further stated that "if learners have sufficient access to L2 input and if it is of vital importance to them to sound like a native speaker of the language they are learning, it is possible that they will attain a nativelike accent, in spite of a late start" (Bongaerts et al., 1997, p. 449). There was no elaboration of the role that motivation might play for these exceptional learners, something that is deserving of further study.

In a study of graduate students learning German, Moyer (1999) placed greater emphasis on motivation. The participants in Moyer's study were assumed to have a high level of motivation due to their professional ambitions (largely as university-level teachers of German, or as interpreters or translators). Only half of the participants reported that native-like pronunciation was very important, with the other half stating that the ability to be understood by native speakers was important, but native-like pronunciation was unnecessary, and achieving it unlikely (Moyer, 1999). The only participant who scored within the range of native speakers on a test of phonology was discarded in the analysis of the results (as an outlier). Interestingly enough, not only did his abilities far outstrip those of the other participants in the study, but his self-reported motivation was significantly different as well. Rather than the instrumental motivation 
cited by the majority of the participants, he "cited a strong desire to acculturate and to sound German” (Moyer, 1999, p. 98), which was a goal that wasn’t shared by the other participants. Moyer continued on to state that "such integrative motivation is difficult to quantify, much less to influence, and its relationship to ultimate attainment has yet to be determined" (1999, p. 98).

Despite the important role the participant's motivation appeared to play in the acquisition of native-like pronunciation, no further investigation was made.

Abu-Rabia and Kehat (2004) had findings similar to those of Bongaerts et al. $(1995,1997)$. In a study of late learners of Hebrew, they found that some of their participants did score within a native range of pronunciation when rated by a panel of native speaker judges. The most interesting part of this was the fact that the participant who had been youngest upon age of arrival ( 7 years old, as opposed to participants in their teens, twenties, or older) scored lower on many of the tests of pronunciation than some participants who had begun learning the language at an older age. Two of the participants who scored particularly high on the pronunciation tests were remarkable in the fact that they had both begun their study of the language after the onset of puberty. Abu-Rabia and Kehat noted that these participants had indicated that "it was very important for them to sound native-like" (p. 96). Their reasons for this motivation, however, were not explored, nor was the motivation of the other participants mentioned. Furthermore, there have been no studies that address exceptional learners of Japanese. Researchers have examined Arabic (Ioup et al., 1995), English (Bongaerts et al., 1995, 1997), German (Moyer, 1999), and Hebrew (Abu-Rabia \& Kehat, 2004), but none have addressed Altaic languages. If we are to gain a better understanding of both 
pronunciation in exceptional learners and the role that motivation may play in the acquisition of pronunciation, examining these phenomena in a wider range of languages would serve us well.

\section{Rationale}

As becomes clear even in this brief review of literature concerning motivation, attitudes, accent and successful late learners of a second language, much has been accomplished, but more remains to be done, particularly in the area of pronunciation. The relationship between motivation and achievement in pronunciation, an area in which it is thought to be especially difficult for late learners to succeed, has yet to be explored in much detail. The relationship between attitudes and achievement in pronunciation is also largely under-explored. Furthermore, the specific group that I investigated (successful English-speaking late learners of Japanese) had yet to be studied with respect to pronunciation.

Moyer (1999) explicitly stated that motivation in highly successful late learners was an area in need of "more focused investigation as a significant factor in ultimate attainment” (p. 100). A number of other researchers (Abu-Rabia \& Kehat, 2004; Bongaerts et al., 1995; Bongaerts et al., 1997; Ioup et al., 1994; Schneiderman \& Desmarais, 1988a, 1988b) have also made specific mention of the importance of motivation in their participants' successful acquisition of a second language as adults, but did not address types of motivation, or seek to discover which types of motivation might have had this effect. For my own research, I conducted a study to help fill these gaps left 
by previous research, by exploring the connections between motivation and success in pronunciation of a second language in a context left previously unexplored.

In order to explore these connections, I drew from the methodology of a number of the researchers addressed previously, most notably the Academic Motivation Scale (Vallerand et al., 1989) to measure intrinsic and extrinsic motivation, the mini Academic Motivation Test Battery (Gardner \& Lambert, 1972; Gardner \& MacIntyre, 1993) to measure integrative and instrumental orientation, the Pronunciation Attitude Inventory (Elliot, 1995a; 1995b) to measure attitudes toward pronunciation, and finally a test of accent developed by Bongaerts et al. (1995; 1997). The three questionnaires (the AMS, mini-AMTB, and PAI) have all been employed in foreign language contexts, and have been tested for reliability. The test of accent I used was employed in multiple studies by Bongaerts et al. (1995; 1997), with a variety of participants and judges. It was for this reason, as well as its applicability and ease of use that I chose to use this methodology to collect speech samples for the present study. Bongaerts et al. $(1995 ; 1997)$ provided their Dutch-speaking participants with six sentences containing a variety of phones, and asked these participants to repeat each sentence three times, though they used only two versions in the rating process. Participants were given only a moment to look over the sentences, and were not able to practice the sentences aloud before recording them. The recorded sentences were then randomized and played for a panel of judges, who rated the sentences on a 1 to 5 scale, with 1 indicating a very strong non-native accent, and 5 indicating no accent whatsoever. This scale is the same one that I employed in my study, and is again discussed in more detail in the following chapter. Despite Bongaerts et al.'s results indicating exceptionality and their brief speculation regarding the role that 
motivation might play for these exceptional learners, Bongaerts et al. (1995; 1997) paid very little attention to the potential interplay between motivation and accent, which is exactly what I aimed to explore in my study.

\section{Research Questions}

The purpose of my study was twofold: First, I hoped to contribute to the existing literature regarding pronunciation, motivation, and attitudes toward pronunciation in late learners of a second language. Second, I wished to gain a better understanding of those types of motivation and the attitudes which may lead to native-like pronunciation among a group that has been largely left unexplored: English-speaking late learners of Japanese. The research questions I specifically addressed are as follows:

1. Is there a correlation between motivation as measured by the two major theories of motivation with ratings of accentedness in Japanese as spoken by Englishspeaking late learners? In particular,

a. Does motivation as defined by SDT and measured by the Academic Motivation Scale (Vallerand et al., 1989) correlate with ratings of accentedness?

b. Is there a difference between intrinsic and extrinsic motivation and their correlation with ratings of accentedness?

c. Does integrative/instrumental orientation as measured by the mini Academic Motivation Test Battery (Gardner \& Lambert, 1972; Gardner \& MacIntyre, 1993) correlate with ratings of accentedness in Japanese? 
d. Is there a difference between integrative and instrumental orientation and their correlation with ratings of accentedness?

2. Is there a correlation between attitudes toward pronunciation as measured by the Pronunciation Attitude Inventory (Elliot, 1995a, 1995b) and ratings of accentedness in Japanese as spoken by English-speaking late learners? 


\section{Chapter 3}

\section{Methodology}

This study was designed to be a correlational examination of the following variables: intrinsic and extrinsic motivation, integrative and instrumental orientation, attitudes toward pronunciation, and accent in English L1 late learners of Japanese. The following chapter describes the context in which I undertook my study, the participants and judges, and my data collection and data analysis methods.

\section{Context and Participants}

My study took place in the Japanese department of a university in the Pacific Northwest. I selected 10 participants on a volunteer basis from the senior and graduatelevel Japanese Speaking and Listening classes, though there were some qualifying criteria. The qualifying criteria, described below, allowed me to control for native language and early exposure to the language, though I was not able to control for time

spent in Japan. Reasons for exclusion included the following: speaking a native language other than English (to control for influences that may be more phonologically similar to Japanese than English); substantive exposure to Japanese before the age of 12, as with a native-speaker parent; or intensive instruction, as in immersion experiences or intensive Japanese language classes, before the age of 13. Due to the limited size of the potential pool of participants, students who had spent time abroad were not excluded.

Of the 10 participants, seven were female and three were male. They ranged in age from 20 years to 30 years, with an average of approximately 24 . The age of initial 
study of Japanese varied from 14 years old to 26 years old, with an average of 18.5 years. Time spent studying Japanese in a formal context ranged from just over one year to nearly eight years, with an average of approximately 5 and a half years. Four participants had no experience abroad, and the greatest amount of time spent abroad by any was three years. Average time spent in Japan (for all participants) was approximately nine months. I also asked six native speakers of Japanese to participate in the study. One of these native speakers acted as a preliminary judge in selecting sentences from the recorded samples for further rating, as well as a native speaker control during the accent rating. The other five acted as judges for the accent rating portion of my study. I elicited volunteers from the university's Japanese department, MA TESOL program, and from the Japanese exchange students participating in intensive English language programs and international cultural service programs. The judges ranged in age from 23 to 50, with an average of approximately 30 years. Their time in the U.S. ranged from 10 months to 27 years, with an average of approximately 8 years. The preliminary judge and native speaker control was from Hokkaido, whereas the other five judges were from Tokyo, Nagoya, Kyoto, and Kumamoto.

\section{Instruments}

I used four instruments to collect data: two motivation scales, one attitude scale, and a test of accentedness. In order to measure motivation, I used a slightly modified version of the Academic Motivation Scale (AMS) developed by Vallerand et al. (1989). The AMS is a questionnaire consisting of 28 items graded on a 7-point Likert-type scale. The AMS was initially designed to measure students' motivation for attending college, 
but has also been used to measure students' motivation for learning a language. Both the AMS and the original French version, the Echelle de Motivation en Education, have been tested for validity and reliability by the original researchers and further verified to be cross-culturally accurate (Vallerand et al., 1992). For my own purposes, I adapted it specifically to measure motivation for learning Japanese (Appendix E). Based on SelfDetermination Theory (Deci \& Ryan, 1985; Deci et al., 1991), the AMS measures seven different areas and types of motivation: intrinsic motivation towards knowledge, accomplishments, and stimulation; external, introjected and identified regulations; and amotivation. There are four items for each subtype of motivation.

The second motivation scale I used was a shortened version of Gardner and Lambert's (1972) Academic Motivation Test Battery (AMTB), commonly referred to as the mini-AMTB (Appendix F). The mini-AMTB is a questionnaire consisting of 11 items, again graded on a 7-point Likert-type scale. It has been used successfully in a number of studies (Hashimoto, 2002; MacIntyre \& Charos, 1996), and demonstrated to be reliable, even in this condensed form (Gardner \& MacIntyre, 1993). I chose to use the mini-AMTB rather than the full version in the interest of time. I adapted it for students of Japanese from Hashimoto's (2002) version, which had been used to measure the motivation of Japanese EFL students. The AMTB measures integrative and instrumental orientation, attitudes toward the class, and language anxiety, though only the integrative and instrumental orientation portions were pertinent to my research questions.

The third instrument was the attitude scale, a slightly modified version of Elliot's (1995a, 1995b) Pronunciation Attitude Inventory (PAI, Appendix G). The PAI was designed to measure students' attitudes toward pronunciation, and gauge the importance 
they place on sounding like a native or near-native speaker of the target language. The PAI has not been widely employed in SLA research at this juncture, though Elliot (1995a, 1995b) found that it was reliable. Out of ten variables. Elliot found that pronunciation attitudes as measured by the PAI were the best indicator of a good (if not native or nearnative) accent in a second language. Elliot initially used it to measure the attitudes of students of Spanish, so it took minimal modification to fit students of Japanese. The PAI consists of 12 items, graded on a 5-point Likert-type scale.

The fourth instrument I used was a test of accentedness, judged by a 5-person panel of native Japanese speakers. As mentioned in my literature review, I modeled this test upon that of a study by Bongaerts et al. (1997), in which the researchers examined near-native pronunciation of English by Dutch L1 speakers who were late learners of English. I recorded participants reading five written sentences in Japanese that were selected from the textbook used in the senior and graduate level Japanese classes. Sentences were selected from the sections that were being used in the class at the time of the study, in order to control for relative familiarity with the material, range of phonological features, and correctness and appropriateness of grammar (shown below). These sentences were provided in romanji, kanji and kana, along with an English translation. The romanji, kanji and kana were provided to ensure that participants could read the sentences in whichever format was most comfortable for them. Reading ability and speaking ability do not necessarily progress at the same rate in learners of Japanese, so in order to maintain focus on pronunciation rather than the reading process, multiple versions were provided. 
Sentences for Recording (from Jorden \& Noda, 1990)

1.あの空、開けようとしましたが、やっぱり開かないんですね！

Anó màdo, akéyòo to shimâsita ga, yáppàri akánài n desu ne!

I tried to open that window, but the fact is it doesn't open, does it!

2.ちようど寝ようとしたところに、電話が入って来ました。

Tyoodo neyóo to sita tokorò ni, deńwa ga hàitte kimasita.

Just at the point when/where I was about to go to bed, a call came in.

3.あのゼミの教室、どこだっけ。

Anó zèmi no kyoositu, dôko da kke.

Where is the classroom for that seminar?

4. 魚を食べることは食べるけど、あまり好きじゃないです。

Sakana o tabêru koto wa tabêru kedo, amári sukì zya nâi desu.

I do eat fish, but I don't like it very much.

5. 明日何時まで手伝いましょうか。正午まででいいですか。

Asita nân-zi made tetúdaimasyòo ka. Syôogo made de îi desu ka.

Until what time shall I help tomorrow? Will (until) noon be all right?

\section{Data Collection}

Data collection occurred in three phases. For the first phase, I held individual recording sessions with each participant, with each session lasting approximately 15 minutes. These sessions were conducted in a soundproof booth. During the first 10 minutes, participants read and signed the informed consent forms (Appendix B), and then completed a brief language learning history (Appendix D), the AMS, the AMTB, and the PAI. The subsequent 5 minutes were devoted to the recording of speech samples. Before beginning the recording, I asked each participant to take a brief moment to look over the sentences, but not to practice them aloud. Participants were allowed to look at the sentences during the recording, but asked not to read them, instead using them as memory prompts as necessary. I recorded each participant repeating each sentence three times, 
discarding the first recitation unless either the second or the third contained errors or slips of the tongue, in which case I instead substituted the first recitation.

For the second phase of data collection, I asked the preliminary judge, a native Japanese speaker, to choose the most native-like recitation from the two recorded sentences. At this time, I also recorded her readings of the sentences, to include as a native speaker control. I then duplicated the recordings of the selected sentences, to establish intra-rater reliability. The duplicates allowed me to ascertain whether the judges were responding the same way to repeated sentences or judging them differently. There were 110 sentences in all: two versions each of five sentences, each recited by 10 participants and one native speaker control. I initially had 11 participants, but due to fidelity issues with the recording, one participant's data (speech samples, AMS, AMTB and PAI scores) had to be discarded. I then randomized these remaining 110 sentences for presentation to a panel of five native speakers to act as judges, in the third phase of data collection.

For this third phase, I met with the five native speaker judges on an individual basis in a soundproof booth. Each session took approximately 30 minutes. I offered a 10minute break at the halfway point in the rating session, but all the judges declined, preferring instead to complete the listening in one sitting. After they had read the informed consent form (Appendix C), I asked each judge to listen to the recordings and rate the speaker's accent on the following 5-point scale, as provided by Bongaerts et al. (1997):

1. Very strong foreign accent: definitely nonnative

2. Strong foreign accent 
3. Noticeable foreign accent

4. Slight foreign accent

5. No foreign accent at all: definitely native

Data Analysis

While Likert scales are usually thought to supply ordinal data, I elected to treat the responses as interval instead. I did this in part because it is convention with the researchers who have previously used the motivation measures I employed in my study

(e.g., Noels et al., 2003), and also because the interval between each rating (e.g., a 6 and a 7 on the AMS) could well be considered even. Due to the non-parametric nature of my data, I chose to run a Spearman rank-order correlation. This test allowed me to see if there were any correlations between motivation as measured by the AMS and accent, between the orientations measured by the AMTB and accent, and finally between the PAI and accent.

Summary

For this study, I modeled my data collection and analysis procedures upon several preceding studies, including those by Bongaerts et al. $(1995,1997)$ and Noels et al. (2003). I used four instruments to measure my participants' motivation, orientation and attitudes toward pronunciation, and then gathered speech samples. The speech samples were later rated for accent, and I correlated these ratings with the data from the motivation, orientation and attitudes measures in order to address my research questions. The results of this analysis are in the following chapter. 


\section{Chapter 4}

\section{Results}

The purpose of this study was to determine if there were any correlations between measures of motivation, pronunciation attitudes and ratings of late second language learners' accents. To do this, I correlated participant scores on the two questionnaires regarding motivation (AMS and $\mathrm{AMTB}$ ) and the one questionnaire on pronunciation attitudes (PAI), with the accented ratings using a Spearman rank-order correlation. The first part of this chapter addresses the descriptive statistics: the results of the three questionnaires and the participants' results on the accent ratings. The second part details the statistical analyses and the correlations between motivation, attitudes, and accent.

\section{Descriptive Statistics}

\section{Motivation and Pronunciation Questionnaires}

To calculate the scores for the AMS, which measures intrinsic motivation, extrinsic motivation, and amotivation on a Likert-type scale, I found both the mean and median of the participants' responses in each of the three categories (Table 2). The highest possible score in any category was 7 , and the lowest possible score was 1 . The means were as follows: intrinsic motivation was $5.37(S D .80)$; extrinsic motivation was 4.09 ( $S D$ 1.16); amotivation was 1.5 (SD 1.02). The highest single score in any of the three categories was a 6.42 in intrinsic motivation (P1). Overall, intrinsic motivation was higher than extrinsic motivation, and both intrinsic and extrinsic motivation were higher than amotivation. This suggests that the participants were highly intrinsically motivated, 
moderately extrinsically motivated, and showed little sign of amotivation, though there was some individual variation. This variation was clearest in the cases of P4 and P5. P4 scored higher on extrinsic motivation (4.25) than intrinsic motivation (3.75), and P5 scored higher on amotivation (4.25) than extrinsic motivation (3.42).

Table 2 Motivation as measured by the AMS

\begin{tabular}{|l|l|l|l|}
\hline & Intrinsic Motivation & Extrinsic Motivation & Amotivation \\
\hline Mean & $5.37(S D .80)$ & $4.09(S D$ 1.16) & $1.5(S D$ 1.02) \\
\hline
\end{tabular}

To calculate the values for the AMTB, I again averaged the participants' responses in the integrative and instrumental orientation categories. The highest possible score was again 7 , and the lowest was 1 . The means were as follows: integrative orientation was 6.1 ( $S D$.47); instrumental orientation was 4 (SD 1.83). Overall, participants showed very high integrative orientation, and moderate instrumental orientation. P7 achieved the high score of 7 in integrative orientation, but only scored 4 in instrumental orientation. Most participants scored higher in integrative orientation than instrumental orientation. P1 was the only participant who scored higher in instrumental orientation than integrative orientation, with scores of 5.67 for integrative, but 6 in instrumental (Table 3).

Table 3 Integrative and instrumental orientation as measured by the AMTB

\begin{tabular}{|l|l|l|}
\hline & Integrative Orientation & Instrumental Orientation \\
\hline Mean & $6.1(S D .47)$ & $4(S D$ 1.83) \\
\hline
\end{tabular}

The third questionnaire was the PAI, which measured students' attitudes toward pronunciation. I calculated the results for the PAI by reversing the three negatively- 
worded items in the questionnaire and then totaling the numerical responses, as was indicated in the instructions (Elliot, 1995a, 1995b). The highest possible score was 60, which would indicate a very positive attitude toward pronunciation, whereas the lowest possible score of 12 would indicate a negative attitude. The mean score was 48.7 (SD 5.52). The highest score of 57 was achieved by P3. The two lowest scores were achieved by P4 (42) and P7 (41), who also had the lowest accent ratings, of 1.38 and 1.94, respectively. The high score of 57 indicates an extremely positive attitude toward pronunciation, whereas the low score of 41 indicates a moderately positive attitude. Table 4 Pronunciation Attitude Inventory results

\begin{tabular}{|l|l|}
\hline & $\begin{array}{l}\text { Pronunciation Attitude } \\
\text { Inventory (PAI) }\end{array}$ \\
\hline Mean & $48.7(S D$ 5.52) \\
\hline
\end{tabular}

\section{Accent Ratings}

For the accent ratings, I calculated a mean score for each participant's two versions of the five sentences, and then averaged these scores over the five judges. These scores are shown in Table 5. Recall that the scale ran from $1=$ strong accent, definitely foreign, to $5=$ no accent, definitely native speaker. The mean score for English-speaking participants (P1 through P11) on all sentences was $2.63(S D .67)$, which indicates that the participants, on average, fell between the categories of "strong foreign accent" and "noticeable foreign accent" on the scale used for the accent rating. The ratings for P12 were excluded from this particular calculation on the grounds of her being the native speaker control. Her average rating across all judges and all repetitions was 4.82, though 
she was, with a few exceptions, generally rated 5 for native speaker. None of the Englishspeaking participants scored as a native speaker; the highest score was a $3.64(\mathrm{P} 1)$, which falls between the categories of "noticeable foreign accent" and "slight foreign accent" on the accent rating scale.

Table 5 Accent ratings per participant and sentence, averaged over judges

\begin{tabular}{|l|l|l|l|l|l|l|}
\hline Participant & Sentence 1 & Sentence 2 & Sentence 3 & Sentence 4 & Sentence 5 & Overall \\
\hline P1 & 3.5 & 4 & 3.9 & 3.5 & 3.3 & 3.64 \\
\hline P2 & 2.8 & 2.6 & 1.7 & 2.4 & 1.9 & 2.28 \\
\hline P3 & 3.7 & 2.8 & 3.5 & 2.9 & 2.7 & 3.12 \\
\hline P4 & 1.6 & 1.6 & 1.2 & 1.1 & 1.4 & 1.38 \\
\hline P5 & 2.4 & 2.5 & 2.1 & 2.0 & 2.8 & 2.36 \\
\hline P6 & 2.8 & 2.5 & 2.8 & 2.9 & 3.4 & 2.88 \\
\hline P7 & 2 & 1.8 & 1.5 & 2.3 & 2.1 & 1.94 \\
\hline P9 & 4.1 & 2.5 & 3.2 & 3.0 & 2.9 & 3.04 \\
\hline P10 & 3.3 & 2.6 & 2.6 & 2.0 & 1.9 & 2.48 \\
\hline P11 & 3.2 & 2.7 & 4 & 2.9 & 2.9 & 3.14 \\
\hline P12* & 4.8 & 5.0 & 4.8 & 4.9 & 4.6 & 4.82 \\
\hline Overall Average (all judges, all sentences, excluding P12) & $2.63(S D .67)$ \\
\hline
\end{tabular}

*P12 = NS control

\section{Inferential Statistics}

\section{First Statistical Analysis}

Spearman rank-order correlations were calculated for accent rating and the three motivation types of the AMS, the two orientations of the AMTB and the scores on the 
PAI, respectively (Table 5). Accent ratings were significantly correlated with intrinsic motivation on the AMS and with the PAI. The correlation with intrinsic motivation on the AMS was rho $=.612 p=.030$, which shows a moderate correlation between intrinsic motivation and accent. The correlation with the PAI was rho $=.815, p=.002$, which indicates a strong correlation between attitude toward pronunciation and accent (see Figure 1 for the trend line). These results are consistent with those of Elliot (1995a, 1995b), in that attitude for pronunciation appears to be the most significant indicator of a relatively proficient accent in Japanese.

Accent ratings were not significantly correlated with extrinsic motivation or amotivation on the AMS, or with either type of motivation measured by the AMTB. 


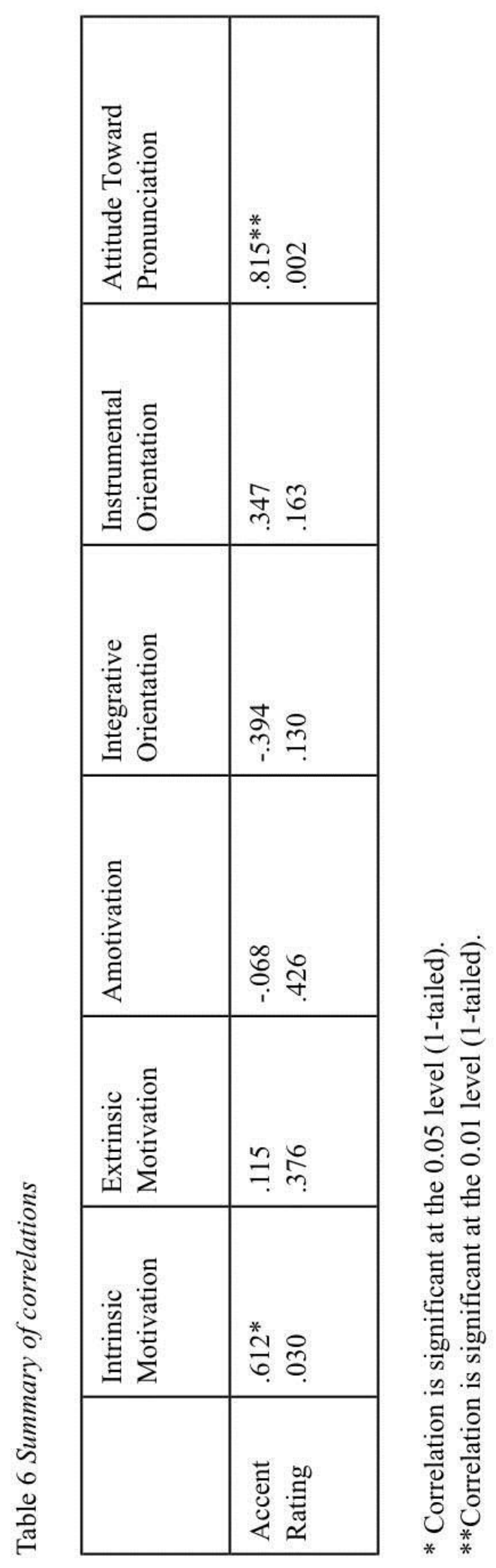


Figure 1 Trend line of accent rating and Pronunciation Attitude Inventory results

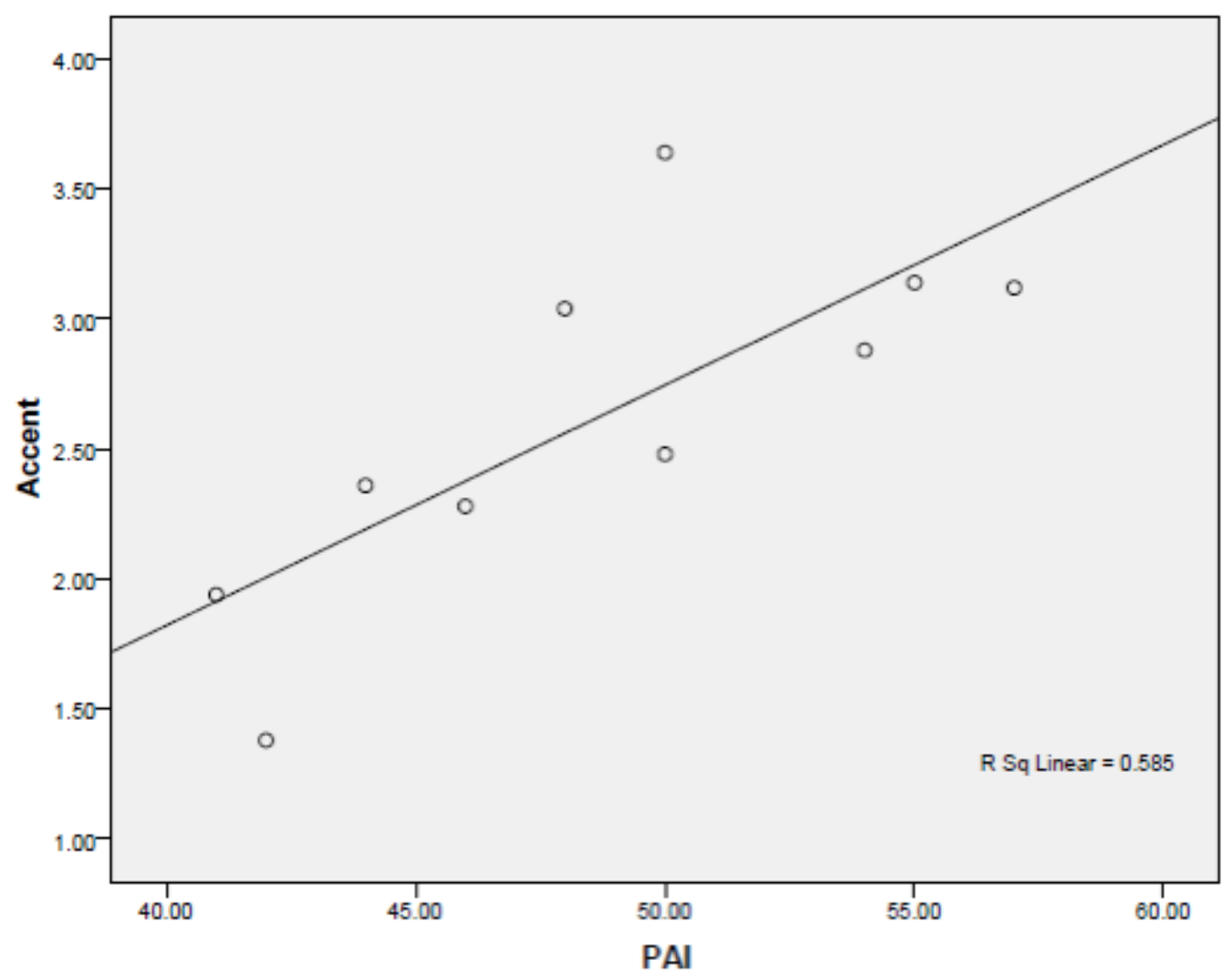

Second Statistical Analysis

Upon finding that accent rating correlated significantly with intrinsic motivation as measured by the AMS, I ran a second round of Spearman rho correlations to see whether any of the three subtypes of intrinsic had a significant correlation with the accent ratings. The participants' individual scores for each subtype are available in Table 5: intrinsic motivation to know, intrinsic motivation towards accomplishments, or intrinsic motivation to experience stimulation. The mean score for intrinsic motivation to know was 5.83 (SD 1.11). The mean score for intrinsic motivation toward accomplishment was 
$5.28(S D$.59). The mean score for intrinsic motivation to experience stimulation was 5

(SD 1.04). Scores in all three subtypes were fairly high and relatively close, though intrinsic motivation to know was the highest (Table 6).

Table 7 Three subtypes of intrinsic motivation as measured by the AMS.

\begin{tabular}{|l|l|l|l|}
\hline & $\begin{array}{l}\text { Intrinsic Motivation To } \\
\text { Know }\end{array}$ & $\begin{array}{l}\text { Intrinsic Motivation } \\
\text { Toward Accomplishment }\end{array}$ & $\begin{array}{l}\text { Intrinsic Motivation To } \\
\text { Experience Stimulation }\end{array}$ \\
\hline Mean & $5.83(S D$ 1.11) & $5.28(S D .59)$ & $5(S D$ 1.04) \\
\hline
\end{tabular}

Of these three subtypes, I found that intrinsic motivation toward accomplishments correlated significantly with accent, rho $=.722, p=.009$ (Table 8 , trend line displayed in Figure 2). Neither of the other two subtypes had a significant correlation. The highest score possible in any of the subtypes was 7 , which was achieved by three participants in intrinsic motivation to know: P1, P6, and P7. The highest score achieved in intrinsic motivation toward accomplishment was 6 (P1 and P11). The highest score achieved in intrinsic motivation to experience stimulation was 6.25 (P1 and P6).

Table 8 Summary of intrinsic motivation subtype correlations

\begin{tabular}{|l|l|l|l|}
\hline & $\begin{array}{l}\text { Intrinsic Motivation } \\
\text { to Know }\end{array}$ & $\begin{array}{l}\text { Intrinsic Motivation } \\
\text { Toward Accomplishments }\end{array}$ & $\begin{array}{l}\text { Intrinsic Motivation to } \\
\text { Experience Stimulation }\end{array}$ \\
\hline Accent & .525 & $.722^{* *}$ & .535 \\
Rating & .060 & .009 & .055 \\
\hline
\end{tabular}

** Correlation is significant at the 0.01 level (1-tailed) 
Figure 2 Trend line of accent rating and intrinsic motivation toward accomplishment results

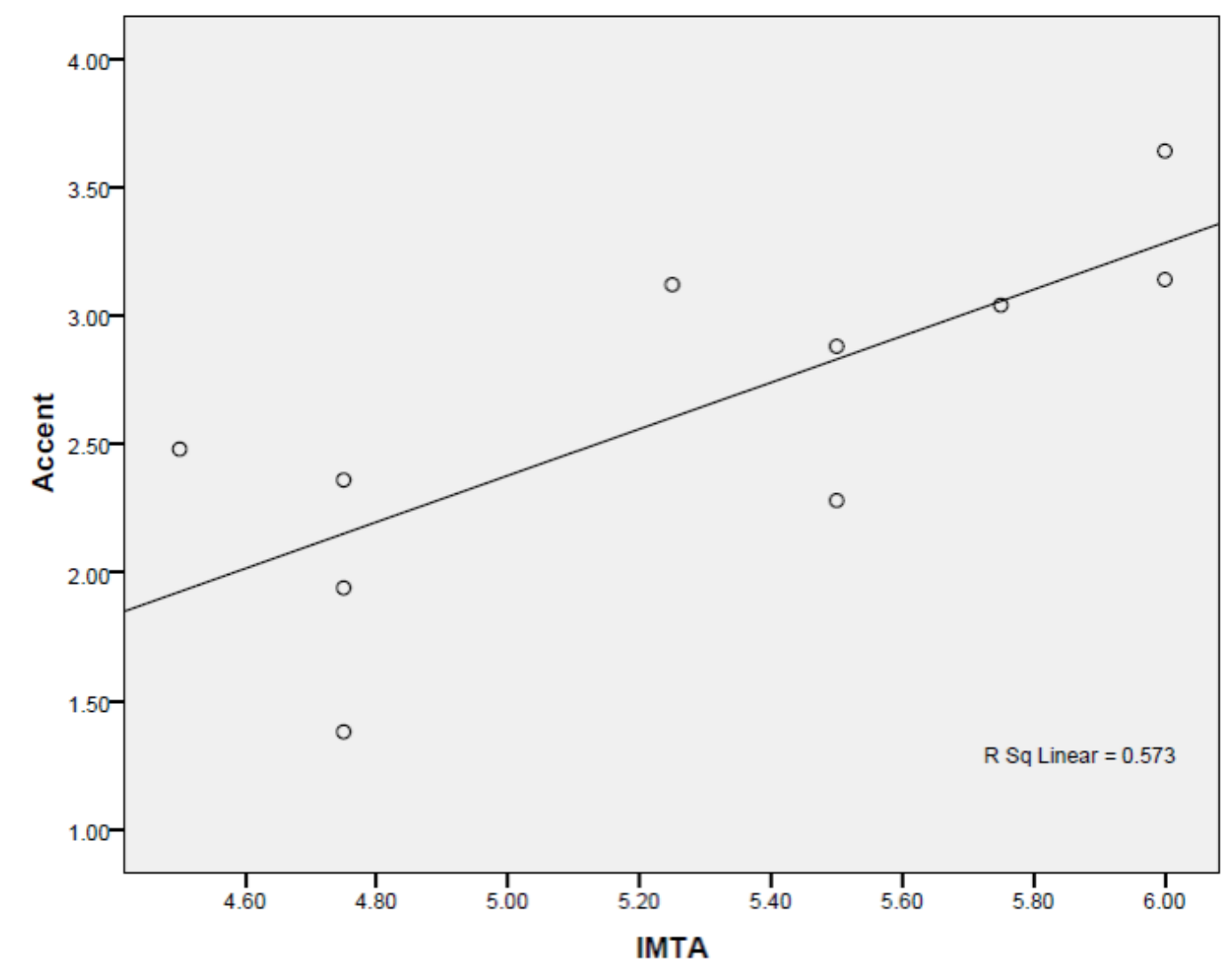

Integrative and Instrumental Orientation and Extrinsic Motivation

Aside from the correlations I was specifically seeking, a separate set of correlations also turned up in the statistical analysis: a significant correlation between instrumental orientation and extrinsic motivation, and interestingly, between integrative orientation and extrinsic motivation. In the case of instrumental orientation and extrinsic motivation, $r h o=.700, p=.012$. In the case of integrative orientation and extrinsic motivation, $\mathrm{rho}=.666, \mathrm{p}=.018$. In each case there was a strong correlation between 
extrinsic motivation as measured by the AMS and integrative and instrumental orientation as measured by the AMTB.

Table 9 Summary of extrinsic motivation and orientations correlations

\begin{tabular}{|l|l|l|}
\hline & Integrative Orientation & Instrumental Orientation \\
\hline Extrinsic Motivation & $.666^{*}$ & $.700 *$ \\
& .018 & .012 \\
\hline
\end{tabular}

* Correlation is significant at the 0.05 level (1-tailed)

\section{Summary}

While none of the participants in this study scored as having a native or native-

like accent in Japanese, there are certain aspects of motivation and attitude that correlated with a relatively good accent. Through statistical analysis, I found that high intrinsic motivation toward accomplishments as measured by the AMS and high positive attitudes toward pronunciation as measured by the PAI both correlated significantly with a good accent in Japanese. 


\section{Chapter 5}

\section{Discussion}

This study was designed to explore two hypothesized correlations: one between motivation and accent, and the other between attitude and accent. More specifically, I investigated accent and motivation in light of two major theories (SDT and integrative vs. instrumental orientation), with the prediction that higher motivation would correlate with highly proficient pronunciation in English L1 late learners of Japanese. I further hypothesized that a similar correlation might be found between a positive attitude toward pronunciation and highly proficient pronunciation. My research questions were as follows:

1. Is there a correlation between motivation as measured by the two major theories of motivation with ratings of accentedness in Japanese as spoken by Englishspeaking late learners? In particular

a. Does motivation as defined by SDT and measured by the Academic Motivation Scale (Vallerand et al., 1989) correlate with ratings of accentedness?

b. Is there a difference between intrinsic and extrinsic motivation and their correlation with ratings of accentedness?

c. Does integrative/instrumental orientation as measured by the mini Academic Motivation Test Battery (Gardner \& Lambert, 1972; Gardner \& MacIntyre, 1993) correlate with ratings of accentedness in Japanese? 
d. Is there a difference between integrative and instrumental orientation and their correlation with ratings of accentedness?

2. Is there a correlation between attitudes toward pronunciation as measured by the Pronunciation Attitude Inventory (Elliot, 1995a, 1995b) and ratings of accentedness in Japanese as spoken by English-speaking late learners?

The results of my study indicate that there is indeed a correlation between motivation and accentedness, as well as between attitudes and accentedness, though only certain types of motivation were correlated with accent ratings. I will answer each question in more detail and then discuss the various limitations this study faces, my recommendations for further research, and the pedagogical implications of my findings.

\section{Research Questions $1 a$ and $1 b$}

Motivation as defined by Self-Determination Theory (SDT) and measured by the AMS correlated significantly with accentedness in the learners of Japanese in this study. In particular, I found a significant correlation between intrinsic motivation toward accomplishment and a highly proficient accent. Recall that intrinsic motivation toward accomplishment is considered highly self-determined behavior according to Deci and Ryan's (1985) description of the subtypes of intrinsic motivation. In other words, learners who exhibit intrinsic motivation toward accomplishment learn for the enjoyment they derive from accomplishing or creating something, in this case, mastering Japanese. There were no other statistically significant correlations, so I concluded that extrinsic motivation is not directly related to accent in Japanese for this population. 
These results are consistent with previous research influenced by SDT, particularly studies by Pae (2008) and Tachibana et al. (1996). Pae found that intrinsic motivation was the variable most related to L2 achievement in Korean EFL learners. He did not investigate the various subtypes of intrinsic motivation, however, and thus gave no further information as to which type of intrinsic motivation accounted for this correlation. Moreover, Pae was examining L2 achievement in general, rather than achievement in L2 pronunciation.

Tachibana et al. (1996) also found that intrinsic motivation was correlated with higher grades (i.e., scholastic achievement) in Japanese and Chinese EFL students, whereas neither extrinsic nor instrumental motivation were. Overall, Japanese students were found to be more intrinsically motivated than Chinese students, who exhibited more extrinsic or instrumental motivation, and the Japanese students with the highest grades also demonstrated the highest intrinsic motivation (Tachibana et al., 1996). Like Pae (2008), Tachibana et al. did not investigate the subtypes of intrinsic motivation, instead measuring it more generally. The methodological differences between their study and my own make it difficult to compare results, though the importance of intrinsic motivation remains.

The correlation between intrinsic motivation and accent stands in opposition to findings by Smit (2002) who determined that the most important variable for pronunciation in EFL learners in Vienna was the perceived relevance of the pronunciation course, rather than motivation. That said, Smit's main goal in the study was to design and test his own tripartite model of motivation, which incorporated 
intrinsic motivation along with extrinsic motivation and integrative orientation into a single component.

The lack of correlation between any subtypes of extrinsic motivation and accent ratings contrasts with the results of Polat (2010), who found a significant correlation between integrated orientation and accent ratings. However, as mentioned in my literature review, there were a number of key differences between my study and that of Polat, particularly the age of the participants (late learners as opposed to early learners) and Polat's specific focus on extrinsic motivation.

\section{Research Questions $1 c$ and $1 d$}

In contrast to the results above, I found that there was no significant correlation between Gardener \& Lambert's (1972) model of integrative or instrumental orientation as measured by the mini-AMTB and ratings of accentedness. Gardner and Lambert (1972) previously demonstrated strong correlations between both integrative and instrumental orientation and achievement in second language, though they did not look specifically at pronunciation.

While it was not one of my research questions, I did find a strong correlation between integrative and instrumental orientation and extrinsic motivation, and so some comparison of the theories is inevitable. Gardner himself has voiced an opinion matched by my findings, stating that integrative and instrumental orientations are both a type of extrinsic motivation, in that regardless of which type of orientation is working, both imply that the learner is engaging in the learning for some specific, outside purpose, rather than simply the enjoyment gained from the learning itself (Gardner, 1985). Pae 
(2008) also had results in accordance with mind, finding that instrumental orientation correlated with external regulation, the least self-determined subtype of extrinsic motivation.

As is evidenced by the results of my study and others (e.g., Gardner, 1985; Pae, 2008), the relatedness of SDT and integrative and instrumental orientation is a potentially important component in achieving a greater understanding of why neither integrative nor instrumental motivation correlate with ratings of accentedness. An understanding of integrative and instrumental orientation as forms of extrinsic motivation could explain my results, in that extrinsic motivation was not significantly correlated with accentedness. All of this serves to illustrate the particularly fitting nature of intrinsic motivation as described by SDT for future veins of research investigating motivation in second language acquisition.

In contrast with my results, a potential relationship between integrative and instrumental orientation and pronunciation has been mentioned by Moyer (1999), though their hypothesized importance was not dealt with in detail. Moyer found that an integrative orientation was associated with native-like pronunciation in German, where as instrumental orientation correlated with a proficient, though non-native-like, accent. The sole participant in her study who demonstrated a native-like ability was discarded as an outlier, and Moyer did not address questions of intrinsic versus extrinsic motivation, framing her discussion of motivation instead within the model of integrative and instrumental orientation. 
Research Question 2

Lastly, attitudes toward pronunciation as measured by the PAI were correlated significantly and strongly with accent. Of the variables included in this study, attitudes toward pronunciation were the most highly correlated with achievement in pronunciation. This mirrors Elliot's (1995a, 1995b) results in his study of learners of Spanish. Elliot found a strong correlation between attitudes and accent, and drew the conclusion that attitudes were the best indicator of achievement in pronunciation.

The correlation between attitudes toward pronunciation and accent is the most predictable of the results. It stands to reason, intuitively speaking, that those students who had a more positive attitude toward pronunciation would be more inclined to put more effort into their pronunciation, and so have great success in acquiring a better, or closer to native-like accent.

\section{Discussion}

The results of this study begin to fill the gap left by many previous studies (e.g., Abu-Rabia \& Kehat, 2004; Bongaerts et al., 1995, 1997; Ioup et al., 1994; Moyer, 1999). Each of these studies has included some brief speculation about the role of motivation in exceptional learners, but none have investigated precisely what type of motivation might contribute to this success. This study offers the beginning of an answer: intrinsic motivation (in particular intrinsic motivation toward accomplishment) correlates strongly with a good accent in proficient learners of Japanese. As mentioned previously, it also provides further support in a different linguistic context for the understanding that a 
positive attitude toward pronunciation also correlates strongly with a good accent in proficient learners of Japanese.

These results provide a unique view into a relatively subtle aspect of L2 learning. While I can make no claims of the predictive power of motivation in achieving pronunciation, this study demonstrates that at least among this group of English L1 late learners of Japanese, intrinsic motivation carries some weight. Motivation is notoriously difficult to characterize, and while we realize that it is highly important in second language acquisition, its importance in the particular area of pronunciation has to date been widely ignored. Admittedly, just how important it is has yet to be determined. One variable not measured in this study was the directionality of the motivation; that is, there is no way of knowing if the motivation preceded the achievement in pronunciation, or if positive feedback on the participants' pronunciation increased their motivation.

In addition to the importance of intrinsic motivation, in this study, I have also demonstrated another context in which a positive attitude toward pronunciation has a clear relationship with accent: that of English-speaking late learners of Japanese as a foreign language. Again, while no predictive statements can be made regarding the connection between attitude towards pronunciation and accent, it does provide us with a greater understanding of another element in the variability present in the pronunciation of late learners of Japanese.

This study also has implications regarding the place of SDT in second language acquisition research. As I have mentioned previously, SDT has only recently been applied to the field of L2 acquisition research, and is still considered far less frequently than Gardner and Lambert's (1972) theory of integrative and instrumental orientation. 
My research adds weight to two reasons researchers should more often consider or rely upon the constructs of SDT: First, SDT is highly applicable in a second language acquisition setting, in that it is able to accurately characterize the motivation expressed by the learners. It was not only intrinsic motivation that correlated with accent in my study, but intrinsic motivation toward accomplishment. Having a more fine-grained classification of the various subtypes of motivation allows researchers to gain a deeper understanding of variability in adult learners, as well as the specific role that any of the various subtypes of intrinsic or extrinsic motivation might play. Intrinsic motivation toward accomplishment is distinct from intrinsic motivation to know or to experience stimulation, and being able to identify this distinction within a population of learners allows for a more accurate view of their motivation.

The second reason we should rely more on SDT is in that the types of motivation described by SDT are distinct from integrative and instrumental orientation. Some researchers may conflate intrinsic motivation with integrative orientation and extrinsic motivation with instrumental orientation, but the results of my study and others (e.g., Gardner, 1985; Pae, 2008) demonstrate that intrinsic motivation belongs in a very separate category than either extrinsic motivation, integrative orientation or instrumental orientation. While this study is admittedly narrow in scope, it does point toward a fairly simple fact: SDT is not only applicable to L2 acquisition research, but under these circumstances the classification of the subtypes of motivation was able to give an especially accurate and detailed portrayal of the motivation expressed by my participants. For these reasons, researchers in L2 acquisition should seriously consider employing the motivation subtypes described in SDT in future research. 
Limitations and Directions for Further Research

This study had a number of limitations. First, the sample was very small, consisting of 10 students. Second, it was necessarily a convenience sample, and it was not possible to control for variables such as time spent abroad or other languages studied. Due to this, the results are not necessarily generalizable, or may be only generalizable to English-speaking students of Japanese as a foreign language. If this same methodology were employed in a context that would allow for greater control of a larger sample, the resulting data might be more representative of a larger population of language learners.

Also, there was a fair amount of variability among the judges, Any discrepancies in accent ratings might be attributable to a number of factors, including either the participants' or the judges' length of residence in the US, or their place of origin in Japan. More specifically, judges might vary on how strict they are depending on how long they have been away from Japan, or it might be a variation in local accent: For example, P12, the native speaker control, is originally from the northern part of Japan, whereas both J2 and $\mathrm{J} 3$ are originally from a more central part of the country. The potential effects of the judges' length of residence in the U.S. and place of origin within Japan were not variables for which I was able to control in this study, given the small potential pool of judges. However, these are variables worthy of future study, and, given time and means, region of origin and length of residence in the U.S. were all variables for which I would have preferred to control.

A further limitation of this study is the fact that ratings were based on a limited sample of speech: scripted sentences in isolation, rather than discourse. If more contextualized or natural language were to be elicited, results might also differ. 
One next step, to further illuminate the precise role of motivation, would be to conduct this same study with beginning learners of Japanese and follow them longitudinally, to test the directionality of this relationship. In other words, does high intrinsic motivation toward accomplishment lead to a good accent in Japanese, or does a good accent in Japanese increase intrinsic motivation toward accomplishment? If this study were undertaken with students who had yet to work on their Japanese accent (i.e., beginning learners without previous exposure to the language), it would be possible to see if the high intrinsic motivation were already present, or if it appears later in the process, once the learners have become proficient in the target language. Another potentially illuminating study would be to investigate the motivation of truly exceptional learners - that is, those who do pass as native speakers in their second language. None of the participants in this study scored within a native range on the test of accent, and so it is not possible to claim with any certainty at this point that this pattern of intrinsic motivation and accent would hold in a different population. A greater understanding of the motivation of exceptional learners could, however, also lead to a greater understanding of why they are exceptional.

Further research could also investigate the role of the classroom and teacher in encouraging either high intrinsic motivation or positive attitudes toward pronunciation. Due to the relatively limited resources available in designing and implementing this study, these were variables that I was unable to address. The participants had varied backgrounds and exposure to different styles/methods of Japanese teaching. The impact that these variables had on students' motivation is unclear. They are, however, worthy of further study, especially given Smit's (2002) finding that students found that the 
perceived relevance of the pronunciation course was a major factor in students' accentedness.

\section{Pedagogical Implications}

Motivation has long been recognized as the most important variable in language learning after aptitude (e.g., Dörnyei, 1994). A crucial difference between these two variables is the potential for a teacher to increase motivation, and thereby increase the likelihood of language learning. Admittedly, my focus in this study was not to determine the role of the teacher or the classroom in the students' motivation, but the fact that intrinsic motivation is related to achievement in pronunciation means that as teachers, we should strive for ways to increase our students' intrinsic motivation. Unfortunately, intrinsic motivation is difficult to inspire in students, due to its very nature: intrinsic motivation comes from within. Educational systems are largely built upon extrinsic motivation: students are required to take a certain number of classes and get a certain grade to pass those classes, and they are therefore "motivated" to attend class and complete their work on time. This imposed system of rewards and punishments extrinsic motivation in its truest form - is frequently detrimental to intrinsic motivation (Dörnyei, 1994). There is also evidence that students who perceive their teacher to be controlling demonstrate less intrinsic motivation as well (Noels, 2001).

However, certain strategies for encouraging self-determined behavior and intrinsic motivation have been suggested, including bolstering learner autonomy and providing positive, informative feedback (Deci \& Ryan, 1985; Noels, 2001). Dörnyei (1994) suggested encouraging learner autonomy by involving students in making 
decisions and establishing priorities. He also recommended that teachers provide their students with the reasons for and practical applications of their learning to encourage students' interest in a given task. These, and many other strategies, may be used to encourage intrinsic motivation in students, which will in turn, hopefully contribute to their achievement in the L2 classroom.

\section{Conclusion}

In this study, I have examined the relationship between motivation as described by two models and accent, and attitude toward pronunciation and accent in a population of highly proficient English L1 learners of Japanese. I have found that there is a strong correlation between both intrinsic motivation toward accomplishment and accentedness ratings and a very positive attitude toward pronunciation and accentedness ratings. These results provide a first step in gaining a better understanding of the variability in pronunciation that is apparent in adult learners of a second language, something that has been remarked upon by numerous researchers, but rarely if ever addressed in detail. It has often been maintained that native-like pronunciation is neither possible (or in some cases desirable), but some researchers have demonstrated that it is entirely possible. While none of the learners in this study were found to have native-like pronunciation, these results nevertheless indicate that this is a path worthy of further research.

The results of this study begin to demonstrate why there is this variability in adult learners: high intrinsic motivation toward accomplishment and a positive attitude toward pronunciation can contribute to a better accent. These two items appear to be key in achieving good pronunciation as a late learner. These results have both theoretical and 
pedagogical implications, and will hopefully contribute to a better understanding of late second language acquisition and the variables that are most important in learners' achievement. 


\section{References}

Abrahamsson, N., \& Hyltenstam, K. (2008). The robustness of aptitude effects in near native second language acquisition. Studies in Second Language Acquisition, 30, 481-509. doi:10.1017/S027226310808073X

Abu-Rabia, S., \& Kehat, S. (2004). The critical period for second language pronunciation: Is there such a thing? Ten case studies of late learners who attained a native-like Hebrew accent. Educational Psychology, 24, 77-98. doi: $10 / 1080.0144341032000146467$

Birdsong, D. (1992). Ultimate attainment in second language acquisition. Language, 68, 706-755. Retrieved from http://www.jstor.org/stable/416851

Bongaerts, T., Planken, B., \& Schils, E. (1995). Can late starters attain a native accent in a foreign language? A test of the critical period hypothesis. In D. Singleton \& Z. Lengye (Eds.), The age factor in second language acquisition (pp. 30-50). Clevedon, Avon, UK: Multilingual Matters.

Bongaerts, T., van Summeren, C., Planken, B., \& Schils, E. (1997). Age and ultimate attainment in the pronunciation of a foreign language. Studies in Second Language Acquisition, 19, 447-465.

Deci, E. L., \& Ryan, R. M. (1985). Intrinsic motivation and Self-Determination Theory. New York: Plenum.

Deci, E. L., Vallerand, R. J., Pelletier, L. G., \& Ryan, R. M. (1991). Motivation and education: The Self-Determination perspective. Educational Psychologist, 26, $325-346$.

Dörnyei, Z. (1994). Motivation and motivating in the foreign language classroom. The 
Modern Language Journal, 78, 273-284. Retrieved from http://www.jstor.org stable/330107

Dörnyei, Z. (2001). New themes and approaches in second language motivation research. Annual Review of Applied Linguistics, 21, 43-59.

Elliott, A. R. (1995a). Field independence/dependence, hemispheric specialization, and attitude in relation to pronunciation accuracy in Spanish as a foreign language. The Modern Language Journal, 79, 356-371. Retrieved from http://www.jstor.org stable/329351

Elliott, A. R. (1995b). Foreign language phonology: Field independence, attitude, and the success of formal instruction in Spanish pronunciation. The Modern Language Journal, 79, 530-542. Retrieved from http://www.jstor.org/stable/330005

Gardner, R. C. (1985). Social psychology and second language learning: The role of attitudes and motivation. London: Edward Arnold Publishers.

Gardner, R. C., \& Lambert, W. L. (1972). Attitudes and motivation in second-language learning. Rowley, MA: Newbury House.

Gardner, R. C., \& MacIntyre, P. D. (1993). On the measurement of affective variables in second language learning. Language Learning, 43, 157-194.

Gardner, R. C., Masgoret, A.-M., Tennant, J., \& Mihic, L. (2004). Integrative motivation: Changes during a year-long intermediate-level language course. Language Learning, 54, 1-34.

Gardner, R. C., \& Tremblay, P. F. (1994). On motivation, research agendas, and theoretical frameworks. The Modern Language Journal, 78, 359-368.

Haraguchi, S. (1999). In N. Tsujimura (Ed.) The handbook of Japanese linguistics (pp. 
1-30). Malden, MA: Blackwell Publishers, Inc.

Hashimoto, Y. (2002). Motivation and willingness to communicate as predictors of reported L2 use: The Japanese ESL context. Second Language Studies, 20, 29-70.

Hibiya, J. (1999). Variationist sociolinguistics. In N. Tsujimura (Ed.) The handbook of Japanese linguistics (pp. 101-120). Malden, MA: Blackwell Publishers, Inc.

Ioup, G., Boustagui, E., El Tigi, M., \& Moselle, M. (1994). Reexamining the critical period hypothesis: A case study of successful adult SLA in a naturalistic environment. Studies in Second Language Acquisition, 16, 73-98.

Jakobovits, L. A. (1970). Foreign Language Learning: A psycholinguistic analysis of the issues. Rowley, MA: Newbury House Publishers.

Jorden, E. H., \& Noda, M. (1990). Japanese: The spoken language (part 3). New Haven: Yale University Press.

Kubozono, H. (1999). Mora and syllable. In N. Tsujimura (Ed.) The handbook of Japanese linguistics (pp. 31-59). Malden, MA: Blackwell Publishers, Inc.

Ladefoged, P. (1982). A course in phonetics (2 ${ }^{\text {nd }}$ ed.). New York: Harcourt Brace Jovanovich, Inc.

Lenneberg, E. H. (1967). Biological foundations of language. New York: John Wiley \& Sons, Inc.

Long, M. H. (1990). Maturational constraints on language development. Studies in Second Language Acquisition, 12, 251-285.

Macintyre, P. D., \& Charos, C. (1996). Personality, attitudes, and affect as predictors of second language communication. Journal of Language and Social Psychology, $15,3-26$. 
Marinova-Todd, S. H., Marshall, D. B., \& Snow, C. E. (2000). Three misconceptions about age and L2 learning. TESOL Quarterly, 34, 9-34. Retrieved from http:/ www.jstor.org/stable3588095

McCawley, J. D. (1978). What is a tone language? In V. A. Fromkin (Ed.), Tone: A linguistic survey (pp. 113-131). New York: Academic Press, Inc.

Moyer, A. (1999). Ultimate attainment in L2 phonology: The critical factors of age, motivation, and instruction. Studies in Second Language Acquisition, 21, 81-108.

Noels, K. A. (2001). Learning Spanish as a second language: Learners' orientations and perceptions of their teachers' communication style. Language Learning, 51, 107-144.

Noels, K. A., Pelletier, L. G., Clément, R., \& Vallerand, R. J. (2003). Why are you learning a second language? Motivational orientations and self-determination theory. Language Learning, 53, 33-63.

Okada, H. (1999). Japanese. In Handbook of the International Phonetic Association: A guide to the use of the International Phonetic Alphabet (pp. 117-119). Cambridge: Cambridge University Press.

Pae, T. (2008). Second language orientation and Self-Determination Theory: A structural analysis of the factors affecting second language achievement. Journal of Language and Social Psychology, 27, 5-27. doi: 10.1177/0261927X07309509

Polat, N. (2010). Gender differences in motivation and L2 accent attainment: An investigation of young Kurdish learners of Turkish. Language Learning Journal, 39, 19-41.

Schneiderman, E. I., \& Desmarais, C. (1988a). A neuropsychological substrate for talent 
in second-language acquisition. In L. K. Obler \& D. Fein (Eds.), The exceptional brain: Neuropsychology of talent and special abilities (pp. 103-126). New York: Guilford Press.

Schneiderman, E. I., \& Desmarais, C. (1988b). The talented language learner: Some preliminary findings. Second Language Research, 4, 91-109. doi:

$10.1177 / 026765838800400201$

Shport, I. A. (2008). Acquisition of pitch accent by American learners. In P. Heinrich \& Y.Sugita (Eds.), Japanese as a foreign language in the age of globalization (pp. 165-187). Tokyo: Deutschen Institut für Japanstudien.

Smit, U. (2002). The interaction of motivation and achievement in advanced EFL pronunciation learners. International Review of Applied Linguistics, 40, 89-116.

Smit, U., \& Dalton, C. (2000). Motivational patterns in advanced EFL pronunciation learners. International Review of Applied Linguistics, 38, 229-246.

Tachibana, Y., Matsukawa, R., Zhong, Q. X. (1996). Attitudes and motivation for learning English: A cross-national comparison of Japanese and Chinese high school students. Psychological Reports, 79, 691-700.

Vallerand, R. J., Blais, M. R., Brière, N. M., \& Pelletier, L. G. (1989). Construction et validation de l'Échelle de Motivation en Éducation (EME) [Construction and validation of the Scale of Motivation in Education]. Revue canadienne des sciences du comportement, 21, 323-349.

Vallerand, R. J., Pelletier, L. G., Blais, M. R., Brière, N. M., Senécal, C., \& Vallières, E. F. (1992). The Academic Motivation Scale: A measure of intrinsic, extrinsic, and 
amotivation in education. Education and Psychological Measurement, 52, 10031017. doi: 10.1177/0013164492052004025.

Vance, T. J. (1987). An introduction to Japanese phonology. Albany, NY: State University of New York Press. 


\section{Appendix A}

\section{Interest Form}

I am conducting a study on motivation and speaking Japanese. Would you be willing to spend 30 minutes to help me out? I need 10-15 people to be recorded speaking Japanese and fill out a few questionnaires about why they study Japanese.

The results will be used to better understand what motivates students to learn. Your instructors will not be told whether or not you participate. This study has nothing to do with your Japanese class or your grades.

Please fill in the information below and return the form to Shannon Guinn-Collins

Check one:

Yes, I think I'd be interested. Please contact me.

No, I'm not interested. Please don't contact me.

\section{Contact information (optional)}

Name

E-mail (please write clearly)

Phone

Best way to contact me: Phone E-mail 


\section{Appendix B}

\section{Participant Informed Consent Form}

You are invited to participate in a research study conducted by Shannon Guinn-Collins, a graduate student from Portland State University (PSU). This study is being conducted in partial fulfillment of the requirements for a master's degree in Teaching English to Speakers of Other Languages, and is being carried out under the supervision of Dr. Lynn Santelmann. The researcher hopes to learn how different types of motivation to learn Japanese may interact with pronunciation and accent. In particular, the researcher is interested in the role of motivation in late learners of Japanese; that is, those students who did not begin to learn the language until after the age of 12. You were selected as a possible participant in this study because you are enrolled in Japanese 411/511.

If you decide to participate, you will be asked to:

- answer one short, open-ended questionnaire today, regarding your background as a student of Japanese

- answer three brief questionnaires regarding your motivation for studying Japanese, as well as how important you consider pronunciation

- speak and have recorded five selected sentences

This whole activity will take about 30 minutes.

Any information that is gathered during this study will be kept confidential. If you choose to participate, you will be assigned a code number, and you will be referred to with this number for the duration of the study, and in the write-up of the results. The recording of your voice will be heard only by the researcher and six judges, who will not have access to any identifying information. Information gathered will be kept in a locked file cabinet, or in a password-protected file on computer.

There is a small risk that someone will find out your name or your answers to the questionnaires. There is also a small risk that you will feel uncomfortable or nervous while having your voice recorded. As mentioned above, every effort will be made to ensure your privacy, and you may stop the recording at any time, or not answer the questionnaire if you choose.

Your participation in this study is voluntary. You do not have to participate in this study, and you may withdraw from it at any time without being penalized. If you decide to stop at any point, it will not affect your course grade, or your relationship with the researcher or your professor.

You will not directly benefit from this study, but you may help us achieve a greater understanding of the role of motivation in learning a second language. 
If you have any questions about your rights as a participant or your participation in this study, please contact the Human Subjects Research Review Committee, Office of Research Sponsored Projects at:

Portland State University

Cramer Hall, Room 111

1721 Broadway Ave.

Portland, OR 97201

503-725-8182

hsrrc@lists.pdx.edu

If you have questions about the study itself, please contact either Shannon Guinn-Collins at 505-948-1056 or at guinncollins@ gmail.com, or Dr. Lynn Santelmann at 503-7254140 or at santelmannl@pdx.edu.

Your signature indicates that you have read and understood the above information and agree to participate in this study. Please understand that you may withdraw your consent at any time without penalty, and that by signing this form you are not waiving any legal claims, rights, or remedies. The researcher will provide you with a copy of this form for your own records.

Signature:

Name (printed):

Date : 
Appendix C

\section{Judge Informed Consent Form}

You are invited to participate in a research study conducted by Shannon Guinn-Collins, a graduate student from Portland State University (PSU). This study is being conducted in partial fulfillment of the requirements for a master's degree in Teaching English to Speakers of Other Languages, and is being carried out under the supervision of Dr. Lynn Santelmann. The researcher hopes to learn how different types of motivation to learn Japanese may interact with pronunciation and accent. You were selected as a possible judge due to the fact that you are a native speaker of Japanese enrolled in the MA TESOL or MA in Japanese programs.

If you decide to participate, you will be asked to listen to recorded sentences in Japanese and assign each sentence a rating based on how native or non-native you perceive the accent to be. There will be approximately 110 sentences in total. The whole activity will take about an hour, with a ten-minute break at the halfway point.

Any information that is gathered during this study will be kept confidential. If you choose to participate, you will be assigned a code number, and you will be referred to with this number for the duration of the study, and in the write-up of the results. The ratings you assign each sentence will be confidential, and the speakers will not know what they are. Information gathered will be kept in a locked file cabinet, or in a password-protected file on computer.

There is a small risk that someone will find out your name or your ratings, but every effort will be made to ensure your privacy. You may also stop the rating process at any point, if you choose.

Your participation in this study is voluntary. You do not have to participate in this study, and you may withdraw from it at any time without being penalized. If you decide to stop at any point, it will not affect your relationship with the researcher or any of your professors.

You will not directly benefit from this study, but you may help us achieve a greater understanding of the role of motivation in learning a second language.

If you have any questions about your rights as a participant or your participation in this study, please contact the Human Subjects Research Review Committee, Office of Research Sponsored Projects at:

Portland State University

Cramer Hall, Room 111

1721 Broadway Ave.

Portland, OR 97201 
503-725-8182

hsrrc@lists.pdx.edu

If you have questions about the study itself, please contact either Shannon Guinn-Collins at 505-948-1056 or at guinncollins@ @mail.com, or Dr. Lynn Santelmann at 503-7254140 or at santelmannl@ pdx.edu.

Your signature indicates that you have read and understood the above information and agree to participate in this study. Please understand that you may withdraw your consent at any time without penalty, and that by signing this form you are not waiving any legal claims, rights, or remedies. The researcher will provide you with a copy of this form for your own records.

Signature:

Name (printed):

Date : 


\section{Appendix D}

\section{Participant Language Background}

1. At what age did you begin your study of Japanese?

2. How long have you studied Japanese?

3. Have you spent any time in Japan, and if so, for how long?

4. Why did you begin studying Japanese? Have your reasons changed since your study began, and if so, how? 
Appendix E

WHY DO YOU STUDY JAPANESE?

Using the scale below, indicate to what extent each of the following items presently corresponds to one of the reasons why you study Japanese.

\begin{tabular}{ccccccc}
$\begin{array}{c}\text { Does not } \\
\text { correspond } \\
\text { at all }\end{array}$ & $\begin{array}{c}\text { Corresponds } \\
\text { a little }\end{array}$ & $\begin{array}{c}\text { Corresponds } \\
\text { moderately }\end{array}$ & $\begin{array}{c}\text { Corresponds } \\
\text { a lot }\end{array}$ & $\begin{array}{r}\text { Corresponds } \\
\text { exactly }\end{array}$ \\
\hline 1 & 2 & & 3 & 4 & 5 & 6
\end{tabular}

WHY DO YOU STUDY JAPANESE?

1. Because with only speaking English I would not find a high-paying job later on.

$\begin{array}{lllllll}1 & 2 & 3 & 4 & 5 & 6 & 7\end{array}$

2. Because I experience pleasure and satisfaction while learning Japanese.

$\begin{array}{lllllll}1 & 2 & 3 & 4 & 5 & 6 & 7\end{array}$

3. Because I think that knowing Japanese will help me better prepare for the career I have chosen.

$\begin{array}{lllllll}1 & 2 & 3 & 4 & 5 & 6 & 7\end{array}$

4. For the intense feelings I experience when I am communicating in Japanese.

$\begin{array}{lllllll}1 & 2 & 3 & 4 & 5 & 6 & 7\end{array}$

5. Honestly, I don't know; I really feel that I am wasting my time by learning Japanese.

$\begin{array}{lllllll}1 & 2 & 3 & 4 & 5 & 6 & 7\end{array}$

6. For the pleasure I experience while surpassing myself in my studies.

$\begin{array}{lllllll}1 & 2 & 3 & 4 & 5 & 6 & 7\end{array}$

7. To prove to myself that I am capable of learning Japanese.

$\begin{array}{lllllll}1 & 2 & 3 & 4 & 5 & 6 & 7\end{array}$

8. In order to obtain a more prestigious job later on.

$\begin{array}{lllllll}1 & 2 & 3 & 4 & 5 & 6 & 7\end{array}$

9. For the pleasure I experience when I discover new ways to communicate in Japanese.

$\begin{array}{lllllll}1 & 2 & 3 & 4 & 5 & 6 & 7\end{array}$

10. Because eventually it will enable me to enter the job market in a field that I like.

$\begin{array}{lllllll}1 & 2 & 3 & 4 & 5 & 6 & 7\end{array}$

11. For the pleasure that I experience when I learn Japanese.

$\begin{array}{lllllll}1 & 2 & 3 & 4 & 5 & 6 & 7\end{array}$

12. I once had good reasons for studying Japanese; however, now I wonder whether I should continue. 
13. For the pleasure that I experience while I am surpassing myself in one of my personal accomplishments.

$\begin{array}{lllllll}1 & 2 & 3 & 4 & 5 & 6 & 7\end{array}$

14. Because of the fact that when I succeed in Japanese I feel important.

$\begin{array}{lllllll}1 & 2 & 3 & 4 & 5 & 6 & 7\end{array}$

15. Because I want to have "the good life" later on, and I think knowing Japanese will help.

$\begin{array}{lllllll}1 & 2 & 3 & 4 & 5 & 6 & 7\end{array}$

16. For the pleasure that I experience in broadening my knowledge about subjects which appeal to me.

$\begin{array}{lllllll}1 & 2 & 3 & 4 & 5 & 6 & 7\end{array}$

17. Because this will help me make a better choice regarding my career orientation.

$\begin{array}{lllllll}1 & 2 & 3 & 4 & 5 & 6 & 7\end{array}$

18. For the pleasure that I experience when I feel completely absorbed by new knowledge of Japanese.

$\begin{array}{lllllll}1 & 2 & 3 & 4 & 5 & 6 & 7\end{array}$

19. I can't see why I study Japanese and frankly, I couldn't care less.

$\begin{array}{lllllll}1 & 2 & 3 & 4 & 5 & 6 & 7\end{array}$

20. For the satisfaction I feel when I am in the process of accomplishing difficult academic activities.

$\begin{array}{lllllll}1 & 2 & 3 & 4 & 5 & 6 & 7\end{array}$

21. To show myself that I am an intelligent person.

22. In order to have a better salary later on.

$\begin{array}{lllllll}1 & 2 & 3 & 4 & 5 & 6 & 7\end{array}$

$\begin{array}{lllllll}1 & 2 & 3 & 4 & 5 & 6 & 7\end{array}$

23. Because my study of Japanese allows me to continue to learn about many things that interest me.

$\begin{array}{lllllll}1 & 2 & 3 & 4 & 5 & 6 & 7\end{array}$

24. Because I believe that knowing Japanese will improve my competence as a worker.

$\begin{array}{lllllll}1 & 2 & 3 & 4 & 5 & 6 & 7\end{array}$

25. For the "high" feeling that I experience while learning Japanese.

$\begin{array}{lllllll}1 & 2 & 3 & 4 & 5 & 6 & 7\end{array}$

26. I don't know; I can't understand what I am doing in Japanese class.

$\begin{array}{lllllll}1 & 2 & 3 & 4 & 5 & 6 & 7\end{array}$

27. Because studying Japanese allows me to experience a personal satisfaction in my quest for excellence in my studies.

$\begin{array}{lllllll}1 & 2 & 3 & 4 & 5 & 6 & 7\end{array}$

28. Because I want to show myself that I can succeed in my study of Japanese.

$\begin{array}{lllllll}1 & 2 & 3 & 4 & 5 & 6 & 7\end{array}$ 
Appendix F

\section{ATTITUDE/MOTIVATION TEST BATTERY (AMTB)}

(shortened version, adapted from Hashimoto, 2002)

DIRECTIONS: Please indicate your opinion after each statement by putting an $\mathrm{X}$ in the space that best describes the extent to which you believe the statement applies to you.

1. If I were to rate my feelings about learning Japanese in order to interact with members of the Japanese-speaking community, I would say it is:

Weak________________________trong

2. If I were to rate my interest in foreign languages, I would say that it is:

Very Low___________________________ Very High

3. If I were to rate my attitude toward members of the Japanese-speaking community, I would say that it is:

Unfavorable :___________________ Favorable

4. If I were to rate my attitude toward my Japanese instructor, I would say that it is: Unfavorable : :__________Favorable

5. If I were to rate my attitude toward my Japanese course, I would say that it is: Unfavorable Favorable

6. If I were to rate how hard I work at learning Japanese, I would characterize it as: Very Little Very Much

7. If I were to rate my desire to learn Japanese, I would say that it is: Very Low :___ Very High

8. If I were to rate my attitude toward learning Japanese, I would say that it is: Unfavorable Favorable

9. If I were to rate how important it is for me to learn Japanese for employment, I would say that it is:

Very Low :_____________________ Very High

10. If I were to rate my anxiety in my Japanese class, I would rate myself as: 
Very Calm___________________________ Very Nervous

11. If I were to rate my anxiety when speaking Japanese, I would rate myself as:

Very Calm___________________________ Very Nervous 


\section{Appendix G}

\section{The Pronunciation Attitude Inventory (PAI)}

(Elliott, 1995)

Please answer all items using the following response categories:

$5=$ Always or almost always true of me

$4=$ Usually true of me

$3=$ Somewhat true of me

$2=$ Usually not true of me

$1=$ Never or almost never true of me

1. I'd like to sound as native as possible when speaking Japanese.

2. Acquiring proper pronunciation in Japanese is important to me.

3. I will never be able to speak Japanese with a good accent.

4. I believe I can improve my pronunciation skills in Japanese.

5. I believe more emphasis should be given to proper pronunciation in class.

6. One of my personal goals is to acquire proper pronunciation skills and preferably be able to pass as a near-native speaker of the language.

7. I try to imitate Japanese speakers as much as possible.

8. Communicating is much more important than sounding like a native speaker of Japanese.

9. Good pronunciation skills in Japanese are not as important as learning vocabulary and grammar.

10. I want to improve my accent when speaking Japanese.

11. I'm concerned with my progress in my pronunciation of Japanese.

12. Sounding like a native speaker is very important to me. 